\title{
Supports of and Barriers to Pursuing a Natural Resource Degree and Career: Perspectives of Culturally Diverse Young Adults
}

Kelly Balcarczyk

West Virginia University

Follow this and additional works at: https://researchrepository.wvu.edu/etd

\section{Recommended Citation}

Balcarczyk, Kelly, "Supports of and Barriers to Pursuing a Natural Resource Degree and Career: Perspectives of Culturally Diverse Young Adults" (2014). Graduate Theses, Dissertations, and Problem Reports. 459.

https://researchrepository.wvu.edu/etd/459

This Dissertation is protected by copyright and/or related rights. It has been brought to you by the The Research Repository @ WVU with permission from the rights-holder(s). You are free to use this Dissertation in any way that is permitted by the copyright and related rights legislation that applies to your use. For other uses you must obtain permission from the rights-holder(s) directly, unless additional rights are indicated by a Creative Commons license in the record and/ or on the work itself. This Dissertation has been accepted for inclusion in WVU Graduate Theses, Dissertations, and Problem Reports collection by an authorized administrator of The Research Repository @ WVU.

For more information, please contact researchrepository@mail.wvu.edu. 


\title{
Supports of and Barriers to Pursuing a Natural Resource Degree and Career: Perspectives of Culturally Diverse Young Adults
}

\author{
Kelly Balcarczyk \\ Dissertation submitted to the Davis College of Agriculture, Natural Resources and Design at \\ West Virginia University \\ in partial fulfillment of the requirements for the degree of \\ Doctor of Philosophy \\ in \\ Forest Resources Science \\ Committee: \\ Dave Smaldone, Ph.D., Chair \\ Steven W. Selin, Ph.D. \\ Chad D. Pierskalla, Ph.D. \\ Kudzayi Maumbe, Ph.D. \\ Jennifer Douglas, Ph.D. \\ Division of Forestry and Natural Resources \\ Recreation, Parks and Tourism Resources Program \\ Morgantown, West Virginia \\ 2014 \\ Key Words: Barriers, Careers, Natural Resources, \\ Social Cognitive Career Theory, Supports
}

Copyright 2014 Kelly Balcarczyk 


\begin{abstract}
Supports of and Barriers to Pursuing a Natural Resource Degree and Career: Perspectives of Culturally Diverse Young Adults
\end{abstract}

\title{
Kelly Balcarczyk
}

Federal natural resource agencies are facing a human resource crisis. Many natural resource professionals are reaching retirement and attracting young adults to fill vacancies may prove difficult. Although currently on the rise from a recent fall, enrollment in natural resource degree programs has not increased overall in the past three decades, which has resulted in a small and possibly shrinking pool of applicants for natural resource positions. In addition, increasingly young adults in the recruitment pool depart from the traditional background of current natural resource professionals (rural-raised, fisheries/wildlife/biologyeducated, angler/hunter, white male) and agency workplace culture has not changed to match this new recruitment pool.

To recruit and retain more young adults and underrepresented groups in the natural resource field, more knowledge must be gained about the specific variables that influence the choice of natural resource majors and careers. Therefore, this study aims to examine the supports and barriers that influence the pursuit of a natural resource degree and career through the lens of the Social Cognitive Career Theory.

Specifically, this study seeks to answer three main research questions (1) What supports and barriers influence natural resource major choice?, (2) What supports and barriers influence natural resource career choice?, and (3) How do perceived supports and barriers regarding choice of the natural resource field differ between natural resource majors and recent hires? 
The findings of the research are presented in the form of three articles for peerreviewed journals. The first article is based on twenty-two interviews with recent hires with the Fish and Wildlife Service. The second is based on twenty-two interviews with undergraduate natural resource majors at West Virginia University and Alabama A\&M University. The final article compares the data from interviews with both recent hires and undergraduates.

By applying the Social Cognitive Career Theory, the first article highlights the supports and barriers that influence the natural resource career path of culturally diverse recent hires. Data revealed that young adults from underrepresented groups perceived unique and more numerous barriers and supports than white males. The second article emphasizes the supports and barriers that influence the choice of and persistence in a natural resource major. Interviews demonstrated that undergraduates from non-traditional backgrounds experienced increased barriers when compared to rural-raised, hunters/anglers in the major. The third article comparing the barriers faced by recent hires and undergraduates emphasizes the similarities between the two groups. The most notable difference between the two groups was that undergraduates experienced increased barriers because of non-traditional backgrounds, whereas recent hires experienced increased barriers because of ethnicity/race.

Based on results from each article, suggestions are made to improve recruitment and retention of young adults and underrepresented groups in the natural resource field. Furthermore, the successful application of the Social Cognitive Career Theory suggests its potential for improving future research on natural resource career choice. 


\section{ACKNOWLEDGEMENTS}

Completing this dissertation was dependent upon the generous support from a number of inspirational people in my life. Those mentioned below and many others have helped and continue to help me in countless ways.

First, I would like to extend my deep gratitude to my committee chair, Dr. Dave Smaldone, for his sound guidance and mentorship throughout the process. I greatly appreciate all of the time, energy, and funding donated by Dave to make this dissertation possible. Similarly, I would like to thank my committee members, Dr. Selin, Dr. Pierskalla, Dr. Maumbe, and Dr. Douglas, for their scholarly advice. Their assistance has allowed me to focus my research and grow intellectually while completing my degree.

I would like to express my sincere appreciation to the research team with the U.S. Fish and Wildlife Service and the National Conservation Training Center. Sandy Spakoff, Dawn Lagrotteria, Drew Burnett, and Scott Owen contributed to the research process by giving significant input to the proposal and plan. The U.S. Fish and Wildlife Service also contributed to the funding of this project.

Lastly, I would like to thank my family and friends for their endless support and encouragement. Without their love and advice, I would not be the person that I am today. A mere expression of thanks to my family and friends is insufficient for what they have given me. 


\section{TABLE OF CONTENTS}

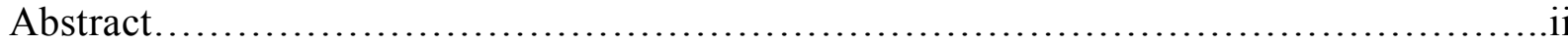



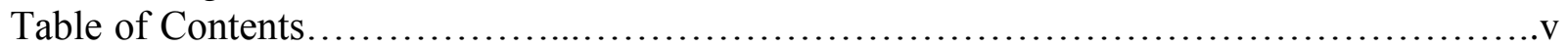





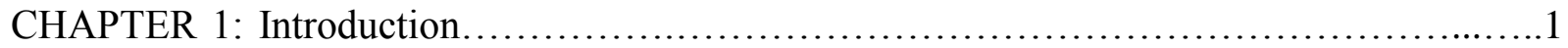

Problem Statement........................................................................

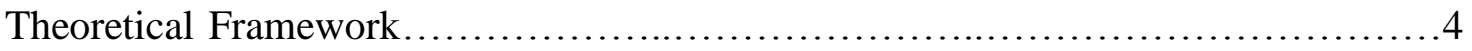

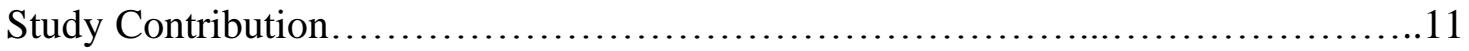

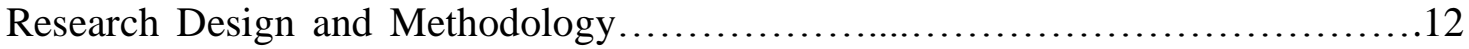

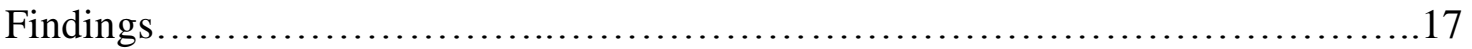

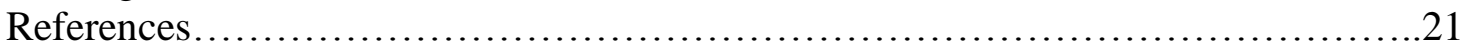

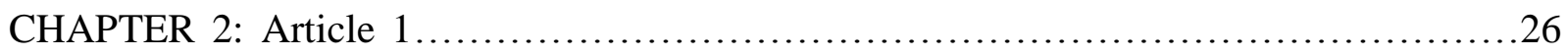

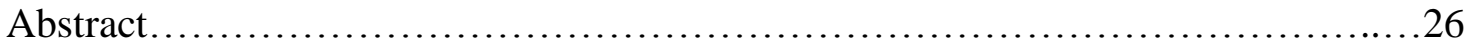

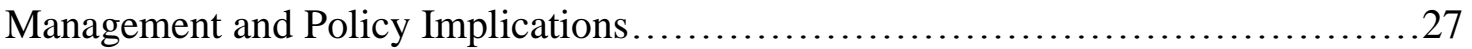

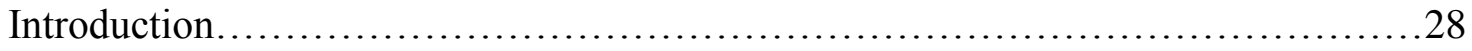

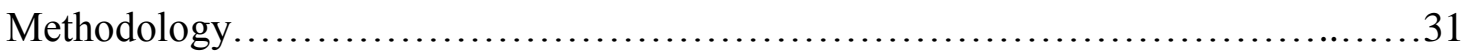

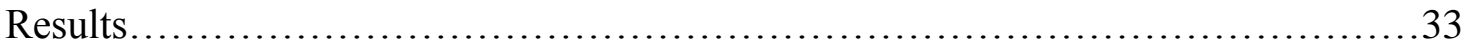

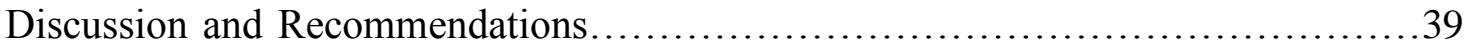

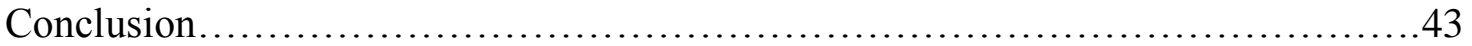

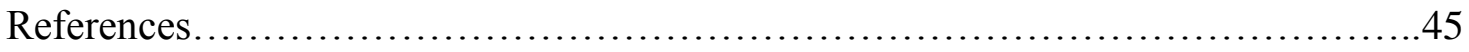

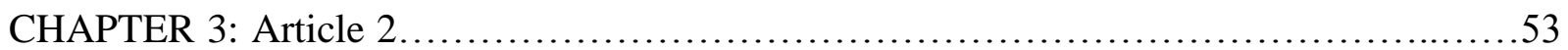

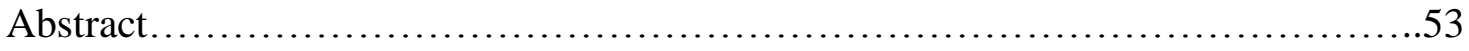



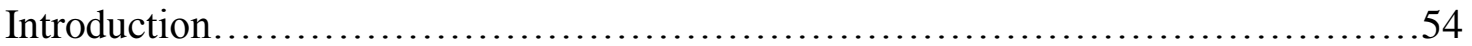

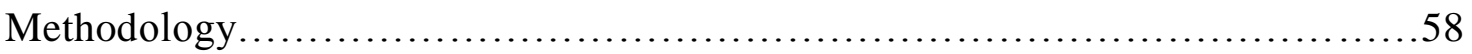

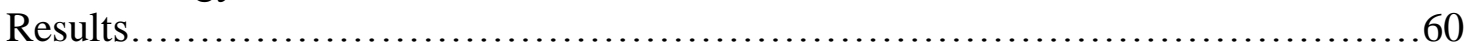

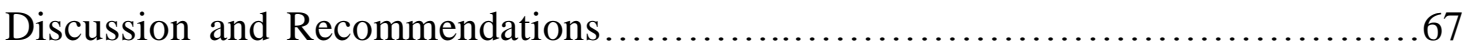

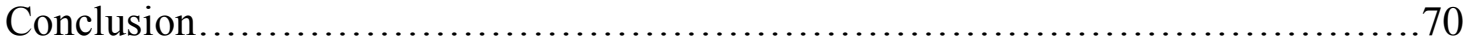

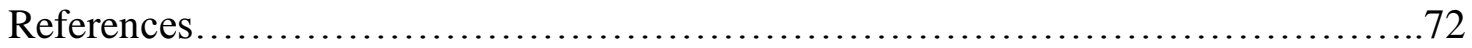

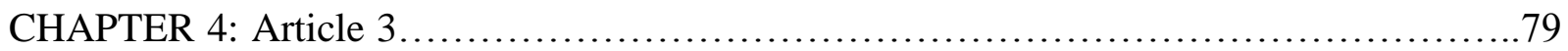

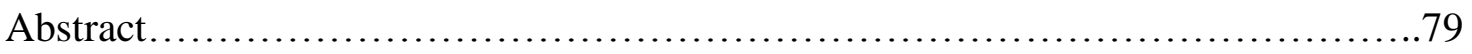



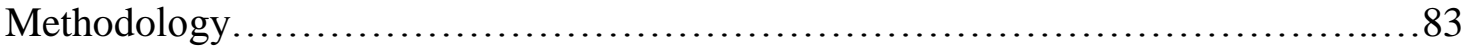

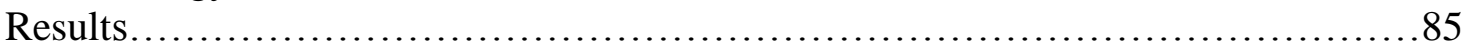

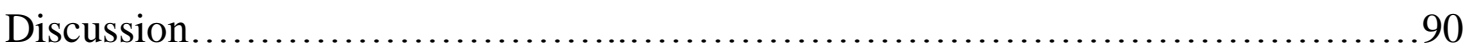

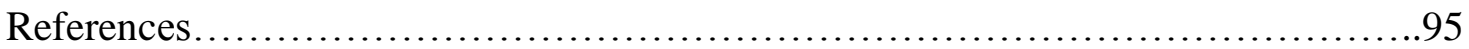

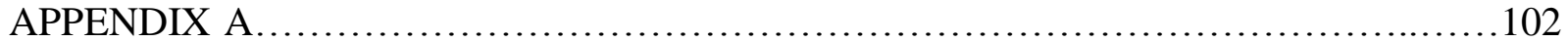

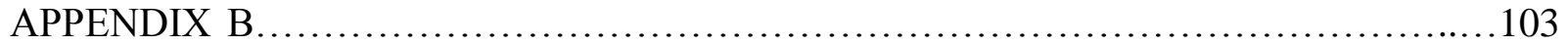



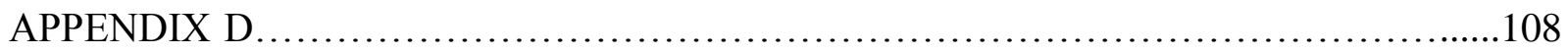




\section{LIST OF FIGURES}

CHAPTER 1: Introduction

Figure 1: The SCCT model of person, contextual, and experiential factors affecting career-

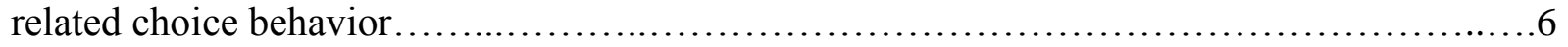

CHAPTER 2: Article 1

Figure 1: Social Cognitive Career Theory Model.....................................49

Figure 2: Barriers to a Natural Resource Career......................................51

Figure 3: Barriers to a Natural Resource Career. ....................................52

CHAPTER 3: Article 2

Figure 1: Social Cognitive Career Theory Model.................................... 75

CHAPTER 4: Article 3

Figure 1: Social Cognitive Career Theory Model....................................98 


\section{LIST OF TABLES}

CHAPTER 2: Article 1

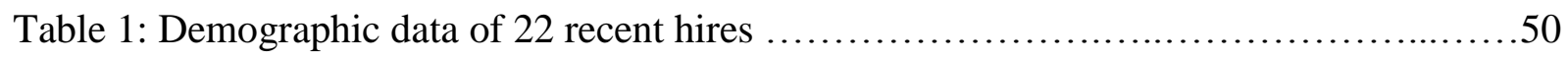

CHAPTER 3: Article 2

Table 1: Demographic data of 22 undergraduate natural resource majors.....................76

Table 2: Barriers to pursuing a natural resource major.................................77

Table 3: Supports to pursuing a natural resource major...............................78

CHAPTER 4: Article 3

Table 1: Demographic data of 22 undergraduate natural resource majors....................99

Table 2: Demographic data of 22 recent hires........................................ 100

Table 3: Barriers to pursuing a natural resource major or career........................101 


\section{CHAPTER ONE: Introduction}

\section{Problem Statement}

Natural resource professions are facing two major problems: a paucity of young adults entering the natural resource field and a lack of diversity in the natural resource field. The pending retirement of many natural resource professionals may result in a loss of institutional memory and core competencies, such as agency leadership and science expertise (Minority Outreach Subcommittee, 1998; Outley, 2008), which can have incalculable consequences for natural resource organizations. In addition, filling the vacancies left by retiring professionals may prove difficult because of a stagnant and declining enrollment in natural resource degree programs over the past three decades (Sharik, 2012). The consequences of reduction in expertise and competencies on the ability of natural resource organizations to solve environmental problems will only be compounded by the lack of cultural and ethnic diversity in the workforce and in natural resource degree programs. Lack of a diverse workforce and student body will further limit the range of solutions considered for environmental problems and likely decrease the ability of natural resource organizations to create innovative solutions (Organization for Tropical Studies, 2007).

Although currently on the rise from a recent fall, enrollment in natural resource degree programs has not increased overall in the past three decades (Sharik, 2012), which has resulted in a small and possibly shrinking pool of applicants for natural resource positions. Natural resource majors are some of the least popular majors among bachelor degree holders with less than one half of one percent of graduates holding a natural resource degree (Carnevale et al., 2011; Sharik, 2012). When combined with agriculture degrees (as natural resource degrees 
often are), the total number of graduates only increases to 1.6 percent of all bachelor degree holders (Carnevale et al., 2011).

One reason for the dismal enrollment numbers in natural resource programs may be the lopsided demographics typically found in these programs. The gender makeup of agriculture/ natural resource degree holders is 70 percent male and 30 percent female: the second lowest percentage of female degree holders when compared to all other major groups (Carnevale et al., 2011). The racial composition of agriculture/natural resource degree holders is even more skewed. Ninety percent of agriculture/natural resource degree holders are White; four percent are Hispanic; three percent are Asian; and two percent are African-American (Carnevale et al., 2011). When compared to all other major groups, the racial composition of agriculture/natural resource majors is more heavily skewed toward White degree holders than any other major (Carnevale et al., 2011).

The racial composition of natural resource degree programs is reflected in the composition of the natural resource workforce. For example, a recent study on diversity in environmental/natural resource institutions (Taylor, 2008) found that approximately onefourth of the 29 government environmental/natural resource agencies and more than one-third of the 129 mainstream environmental/natural resource organizations surveyed had not hired any minorities in the three years preceding the study. Moreover, thirty-five percent of the larger and most widely recognized environmental/natural resource organizations and 19 percent of the government agencies indicated that they had no minorities on staff (Taylor, 2008).

While natural resource programs and organizations struggle to attract young adults and underrepresented groups, the United States is becoming an increasingly racially and ethnically 
diverse country. The disconnect between the population of the natural resource field and the American public highlights the need to change the recruitment and hiring practices in the natural resource profession. Unfortunately, researchers and scholars have historically paid little attention to the significance of diversity for natural resource management and policy (Schelhas, 2002). The lack of attention ethnic and cultural diversity resulted in a failure to realize the many different ways of valuing and using natural resources. Past and present ethnocentrism in the natural resource field fails to embrace the complex linkage between culture, values, social organization, and natural resource use (Schelhas, 2002).

Ethnocentrism in the field has often led to mismanagement of resources and unfair treatment of certain demographic groups, leaving them disenfranchised with the field of natural resources (Schelhas, 2002). In cases of scientific uncertainty in natural resource management, many professionals rely on culturally-coded models developed without consideration of a diversifying population (Fortmann, 1990). The use of culturally coded models has resulted in racial and ethnical discrimination or inconsideration in many aspects of natural resource management, such as natural resource extraction (e.g. Erikson, 1999), outdoor recreation (e.g. Chavez, 2000), tourism (e.g. McLaren, 1999), and natural resource government assistance programs (U.S. Department of Agriculture Civil Rights Action Team, 1997). These historical and current practices of discrimination and inconsideration have left a legacy, which continues to influence people today (Schelhas, 2002). Schelhas (2002) argues that this legacy has resulted in negative perceptions of natural resource management for some demographic groups.

To prevent further inconsideration and one-sided management decisions, it is important that natural resource professionals understand the complex relationships between 
racial and cultural diversity and natural resources. As such, Schelhas (2002) concludes that "it is also important to acknowledge the significant role that increasing racial and cultural diversity among academics and practitioners in the field can play in bringing about this change" (p. 763). To recruit and retain more young adults and underrepresented groups in the natural resource field, more knowledge must be gained on the specific variables that influence the choice of natural resource majors and careers. Career and academic counselors, natural resource organizations and universities, and researchers need to gain a better understanding of the barriers to and supports of pursuing a career in natural resources if the mentioned problems in the natural resource profession are to be fixed.

\section{Theoretical Framework}

Few studies specifically examine supports and barriers influencing academic and career choices in natural resources, with even fewer focusing on academic and career choices of underrepresented groups in the field. Additionally, the studies (e.g. Bowman \& Shepard, 1985; Chesney, 1981; Conroy, 2000) that have examined the influences of supports and barriers on academic and career choices in the natural resource field have lacked the theoretical underpinnings needed to expand hypothesis testing and understanding, as well as provide useful information to career and academic counselors and natural resource organizations.

The applicability of many existing academic and career theories (e.g. Holland's Theory of Vocational Personalities in Work Environment, the Self-concept Theory of Career Development formula, and Gottfredson's Theory of Circumscription and Compromise) to the career development process of diverse groups has been questioned because of lack of 
contextual consideration (Brown, 2000). However, the Social Cognitive Career Theory (SCCT) offers a useful and versatile framework for examining the factors influencing career choice of diverse individuals (Lent et al., 2000). The SCCT is suitable for studying diverse groups pursuing wide-ranging career paths because it examines the individual's career development within his or her cultural and environmental context, while also considering personal agency in the choice process. In addition, because the SCCT considers contextual variables, such as supports and barriers, along with social cognitive variables, it provides a solid foundation for exploring all stages of the career development process (e.g. choosing a college major or career).

In adapting the social cognitive theory to career development, the SCCT conceptualized the personal determinants of the career development process within Bandura's (1986) triadic causal system. The SCCT incorporates three central social cognitive variables (self-efficacy, outcome expectations, and personal goals) from the social cognitive theory and includes interests as an additional building block of career development (Lent et al., 1994; Lent et al., 2002). Furthermore, the SCCT recognizes that social cognitive variables are not solely responsible for shaping vocational outcomes by highlighting important person (e.g. ethnicity, gender) and contextual variables (supports, barriers) (Lent et al., 1994; Lent et al., 2002). The person and contextual variables bi-directionally relate to the social cognitive variables along the path to career development (Lent et al., 2002) (Figure 1).

The core social cognitive (self-efficacy, outcome expectations, interests, goals) and contextual (support, barriers) variables represent the set of influences that are particularly important during the active phases of academic or career decision making (Lent and Brown, 2006) (Figure 1). In other words, the core variables are proximal influences and can be viewed 
as not only a reflection of the distal background variables (environmental/contextual variables, person inputs, and learning experiences), but as current and active processes that can influence key educational and career outcomes, such as choice goals and actions (Lent et al., 1994; Lent and Brown, 2006).

Figure 1



Figure 1. The SCCT model of person, contextual, and experiential factors affecting careerrelated choice behavior. Variables in shaded boxes represent the core/proximal social cognitive and contextual variables. Note that the directional arrows in the framework illustrate what are believed to be the predominant causal pathways; however, based on the triadic casual view, the elements influence one another bi-directionally (Lent et al, 1994). Source. Lent and Brown (2006)

The SCCT model (Figure 1) demonstrates the basic causal sequence of academic and career goal and choice development by illustrating the hypothesized social cognitive determinants of basic interests and the manner in which interests promote career-related activities (Lent et al., 1994). People's perceptions of self-efficacy and outcome expectations figure prominently in the formation of interests (i.e. people will form enduring interests in activities in which they view themselves as efficacious and in which they foresee positive outcomes) (Lent et al., 1994). The SCCT hypothesizes that enduring interests will lead to goals for future exposure or advancement in a certain activity. Further activity exposure will 
lead to an increased likelihood of related task selection and increased likely of choice actions (e.g. choosing a particular college major or career) (Lent et al., 1994; Lent and Brown, 2006). The SCCT posits that the process of interest and goal formation repeats itself over a lifespan, but is probably most fluid up until early adulthood, when academic and career related interests tend to stabilize (Lent et al., 1994). The SCCT also suggests that contextual influences, both actual and perceived, influence the repeating interest and goal formation process throughout the decision making process.

The core contextual influences in the SCCT, supports and barriers, help shape the learning process/experiences that determine personal interests and choices (Lent et al., 1994; Lent and Brown, 2006). Contextual influences are not only the building blocks of the real and perceived opportunity structure within which plans are devised and implemented, but certain contextual factors may exert a strong influence on choice formation and implementation (Lent et al., 1994). Personal perceptions of contextual influences, which are often influenced by person factors (e.g. gender, ethnicity), highlight the importance on the cognitive processes that guide academic and career behavior and choices (Lent et al., 1994; Lent et al., 2000).

Person factors set the context in which career decisions are made by influencing the opportunity structure and evoking differential reactions in the social environment (Lent et al., 1994; Lent et al., 2000). The effects of differences in socio-demographic factors on career interests, goals, and actions may be seen in differential learning experiences and experiences that affect self-efficacy and outcome expectations (Lent et al., 1994).

Environmental and contextual Influences

The SCCT is portioned into two complementary, but distinct levels of theoretical analysis: (1) cognitive person variables, and (2) contextual and behavior variables (Lent et al., 1994). Within the contextual variable analysis, the SCCT posits that career development is 
influenced by both objective (e.g. quality of educational experiences) and perceived (e.g. individual appraisal of educational experiences) environmental factors, highlighting the individual's role in processing both positive and negative environmental influences (Lent et al., 2000; Lent et al., 2006). In conjunction with realizing both the objective and perceived aspects of contextual influences, the SCCT distinguishes between temporal periods during which the contextual influences are acting: (1) distal and (2) proximal (Lent et al., 1994; Lent et al., 2000). Distal, or background, contextual influences affect the academic or career choice through self-efficacy and outcome expectation development, whereas proximal influences are present during the active phase of the decision making process (Lent et al., 2000; Betz, 2008). Conceptually, contextual influences can be divided into two complementary constructs: barriers to and supports of career development.

Contextual variables influence the decision making process even in persons with welldeveloped and differentiated interests in a particular career path. If an individual perceives substantial barriers to the entering of or advancing in a career, they will be unlikely to pursue that academic or career path (Brown and Lent, 1996). However, the way in which barriers interact with contextual supports and influence the overall decision making process can be multifaceted, and dictates the final impact of barriers on academic and career choice (Betz, 2008). Individuals who experience beneficial environmental conditions (presence of ample support, few barriers) are expected to more smoothly negotiate the decision making process than individuals who experience non-supportive environmental conditions relative to academic and career choice because of influence of these conditions on decision making process (Brown, 2002). 
According to SCCT research, contextual variables (barriers and supports) relate to academic and career choice via two paths: (1) direct paths to goal setting and (Lent et al., 1994; Lent et al., 2000) and (2) indirect paths to goals via their linkage to self-efficacy (Bandura, 1999). Past studies of the two paths have more often supported Bandura's (1999) indirect effects path (Lent et al., 2001, 2003, 2005, 2010a, 2010b, 2011; Lent and Brown et al., 2003), indicating the main function of barriers and supports may be to inform self-efficacy, which, in turn, produces either a direct path to choice consideration or an indirect path through outcome expectation and interests (Lent et al., 2010). Only a few studies have shown support of the more direct path between contextual variables and goals, identifying a more proximal impact of barriers and supports (Lent et al., 2005, 2008). Greater support of the indirect path suggests that barriers and supports, even when proximally perceived, influence academic and career choice largely through their effects on self-efficacy rather than by directly hindering or facilitating choice (Betz, 2008).

The pattern in which barriers and supports influence career choice may be one of specificity (pertaining to a particular point in the decision-making process) and immediacy, highlighting the effect of context on the decision maker (Wetterson et al., 2005). In other words, the impact and strength of the influence of supports and barriers on the academic or career decision making process may depend on the life stage of the decision maker. Research suggests that the influence of barriers and supports may only be significant on SCCT variables that are applicable to the individual's life in the moment (e.g. Ali et al., 2005; Wetterson et al., 2005). For example, some SCCT research with high school students has shown insignificant effects of perceived barriers on SCCT variables, such as career choice, outcome expectations, and self-efficacy (Ali et al., 2005; Flores et al., 2006). Barrier effects may not have been 
supported in these studies because high school students are not in an active, decision-making stage of the academic and career development (Oetting, 2008). Nevertheless, despite the influence of decision-making stage, patterns have emerged throughout barrier and support research with diverse populations and maturity levels.

Barriers, defined as "events or conditions, either within the person or in his or her environment, that make career progress difficult" (Swanson and Woitke, 1997; p. 434), have long been recognized to play a significant role in the career decision making process (e.g. Matthews and Tiedeman, 1964; Hackett and Betz, 1981). Interest in barrier research has increased in recent decades (e.g. Swanson et al., 1996; Swanson and Woitke, 1997). However, early research lacked a firm theoretical framework into which research findings could be incorporated and from which hypotheses could be derived (Swanson et al., 1996). More recently with the advent of the SCCT and Lent et al.'s (2000) emphasis on the conceptualization and role of barriers and supports, many studies have been applying the SCCT to barrier research.

Supports, defined as contextual variables that can facilitate the formation and pursuit of an individual's academic and career choices (Lent et al., 2000), have long been recognized in career development literature (e.g. Hawley, 1972). Unfortunately, supports have received far less study than career barriers, which may have limited the understanding of contextual effects on academic and career choices. The lopsided focus on barriers in the literature stemmed largely from the need to explain factors that blocked the pursuit of certain career paths by women (Hackett and Betz, 1981) without consideration of the importance of understanding factors that serve to facilitate the choice of those careers (Lent et al., 2000). 


\section{Study Contribution}

The underrepresentation of minority populations and young adults in natural resource careers has generated national concern among state and federal agencies and within the academic community (Adams and Moreno, 1998), highlighting the need to understand factors influencing natural resource career choice among various underrepresented groups. To date, the limited research on the barriers and supports to choosing a natural resource major or career has been largely atheoretical, leaving the field open to in-depth exploration. This study increased understanding and inform academic and career counseling practices in the much needed area of natural resource career choice through the application of the SCCT. As well as provide valuable insight to natural resource agencies and organizations, to improve their recruitment and retention of young adults from diverse groups.

The SCCT provides an effective lens through which to view the supports and barriers to natural resource careers among diverse groups because of the emphasis placed on socialcontextual factors influencing the formation and implementation of career choices. This study contributed to SCCT research and theory development by identifying barriers and supports that decision makers view as relevant to academic and career choice. Identifying supports and barriers has been recognized as an aspect of the SCCT needing further study (Swanson and Gore, 2000). Additionally, following suggestions by Lent et al. (2000), this study assessed barriers in relation to specific tasks and choice options (i.e. choice of college major and choice of career). Examining barriers in relation to specific tasks will ensure barriers correspond to the outcome of interest through the examination of relevant criteria, such as content and time frame. In addition, this study complemented the study of barriers with the study of supports. By following Lent et al.'s (2000) suggestions, the findings from this study not only advance 
knowledge on supports and barriers, but are also useful to future researchers in the SCCT field. Finally, this research answered the call to establish how SCCT variables apply to persons of diverse cultures and across different levels of academic and career activity, through the sampling to various ethnic groups and young adults of differing employment status (i.e. students and recent hires) (Lent et al., 2010).

The study of perceived and actual barriers and supports was usefully approached using qualitative methods, such as interviews (Lent et al., 2000). Qualitative interviews were particularly useful when studying recently conceptualized constructs, such as SCCT barriers and supports, because of a lack of developed and tested quantitative scales of measure. Moreover, SCCT researchers are not able to rely on all-purpose measures and often have to design new measures depending on the unique features of the behavioral domain of interest (Lent and Brown, 2006). Due to the lack of SCCT research in the natural resource domain, this qualitative study can be used to guide the development of natural resource domainspecific barrier and support scales of measurement.

\section{Research Design and Methodology}

The purpose of this study is to understand the barriers and supports to pursuing a natural resource career. In addition, this study seeks to explore the influence of sociodemographic factors on the supports and barriers encountered along the path to a natural resource career. The following research questions will guide the research design and methodology:

1. What supports and barriers influenced a natural resource major's decision to pursue a natural resource major (article 2)?

a. Do socio-demographic factors influence perceived supports and barriers regarding the pursuit of a natural resource major? 
i. How do socio-demographic factors influence perceived supports and barriers?

2. What supports and barriers influenced a recent hire's decision to pursue a natural resource career (article 1)?

a. Do socio-demographic factors influence perceived supports and barriers regarding the pursuit of a natural resource career?

i. How do socio-demographic factors influence perceived supports and barriers?

3. Do perceived barriers regarding choice of a natural resource field differ between natural resource majors and recent hires at a natural resource organization (article 3)?

a. How do perceived supports and barriers regarding choice of a natural resource field differ between natural resource majors and recent hires?

The specific methods used for each article will be discussed in the following chapters. However, a basic interpretive qualitative research design (Merriam, 2002; Patton, 2002) served as the methodological approach for this study. The qualitative research design gave this study the flexibility to collect information through personal communication, which resulted in vivid and colorful illustrations of subjects' lived experiences during the major and career decision making process (Merriam, 2002; Patton, 2002). Vivid and in-depth data allowed the complexities of choosing a career in natural resources experienced by young adults from diverse socio-demographic backgrounds to be analyzed and made applicable to diverse interest groups: researchers, college administrators/educators, career counselors, and natural resource organizations.

$\underline{\text { Trustworthiness }}$

Guba and Lincoln (1981) emphasized that qualitative inquiry should be judged by trustworthiness, which is a combination of credibility, transferability, dependability, and confirmability. To ensure credibility of the research findings, member checking with select recent hires and students was used. Following data collection, preliminary findings were reported back to the participants, asking for critical comments on the identified support and 
barrier themes, which were incorporated into final findings (Kuzel and Like 1991). The issue of transferability was addressed by providing detailed research methods, contexts, and assumptions underlying the study (Guba and Lincoln, 1981). Triangulation, or using multiple informants ( 22 students and 22 recent hires) from culturally and ethnically diverse groups, helped to validate and confirm the dependability of the research. Triangulation allowed me gather multiple perspectives in order to gain a more complete understanding of the phenomenon natural resource major and career choice (Kuzel and Like, 1991). I also incorporated investigator triangulation in order to determine if other researchers view the phenomenon in a similar way. My advisor and another committee member reviewed the coding schemes that I develop during data analysis. The incorporation of investigator triangulation at the data analysis level, may also add theory triangulation to my research. My advisor and committee members come from different research backgrounds and different theoretical viewpoints. Confirmability of the research was addressed by establishing a trail of evidence (notes, transcripts, recordings) allowing another researcher to arrive at similar findings using the same data and documents (Guba and Lincoln, 1981). In addition, data coding was peer reviewed to establish inter-rater reliability (Stemler, 2001).

Role of the Researcher

In qualitative research, the researcher is the instrument of both data collection and data interpretation (Bogdan and Biklen, 2003). Therefore, in any qualitative research it is essential to understand how the researcher's experiences influenced the data collection and interpretation process. This section will give an overview of my perspective when approaching this research. 
My experience as a female with degrees in a natural resource-related field may influence the way in which I conducted the study, interacted with participants, and analyzed and interpreted the data. Holding a bachelor's and master's degree in biology, I have an appreciation for the difficulty of pursuing and persisting in a college major that demands academic rigor similar to that of a natural resource major. In addition, while currently in pursuit of my doctoral degree in forest resource science, I am witnessing the supports needed and barriers encountered along the path to a career in natural resources. As a female, throughout my academic career, I have been an underrepresented minority, which may have allowed me to empathize with underrepresented minorities in this study.

After obtaining my bachelor's and master's degrees, I pursued work in natural resource-related fields and encountered barriers to finding a fulfilling career path. The ways in which I overcame the barriers that I encountered has allowed me to understand that everyone's path to a natural resource career is unique. However, it may have influenced the way in which I conducted and analyzed the interview with both recent hires and students. It is my hope that this research highlights the unique paths the participants took toward a natural resource career.

Because of my experience in the natural resource field as a student and professional, I was able to gain entrée with my research participants. I was familiar with terms, scenarios, and programs discussed by research participants. Entrée allowed me to develop a rapport with interview participants, which may have resulted in a more comfortable and open interview setting.

\section{$\underline{\text { Limitations }}$}

This study includes a number of limitations endemic to qualitative research: 1) the researcher's role, 2) theory choice, 3) purposeful sampling/sample selection, 
4) generalizability of findings, and 5) accuracy and truthfulness of the answers. 1) My role as the researcher may have influenced the way the data was collected, analyzed, and interpreted. 2) In choosing to analyze data under the guidance of the Social Cognitive Career Theory, the findings may be biased toward fitting that theory, while not considering others. 3) The criterion used for sample selection limited the sample to students and recent hires that are currently in a natural resource major or organization; eliminating students who transferred from a natural resource major or employees who changed career paths after failing to succeed in finding a career with a natural resource organization. The elimination of this group may result in failure to find barriers that may be very difficult overcome along the path to a natural resource career. 4) The study findings may not be generalizable to the larger population of natural resource students and recent hires in a natural resource career. 5) Participants controlled the accuracy and truthfulness of the answers. Although confidentiality was assured, participants may not have answered honestly and completely.

\section{Delimitations}

The delimitations of this study were established through the selection of the theory, research questions, and proposed methods. The study questions, interview questions, and data analysis and interpretation were guided by the Social Cognitive Career Theory. A number of career theories are available and widely used in research today; however, the SCCT effectively takes contextual variables (such as socio-demographic factors, barriers, and supports) into account when seeking to understand career choice. Contextual variables influencing career choice are the main component of this research. Additionally, although a number of interesting research questions could have been generated from the SCCT, the problem of interest led to the delineation of the specific research questions stated above. 
This study used an accessible sample of natural resource majors at West Virginia University and Alabama A\&M University, and recent hires at the U.S. Fish and Wildlife Service who meet the sampling criterion. Samples were selected for this study based on accessibility. The researcher is a student at West Virginia University and working on a project with the U.S. Fish and Wildlife Service. Due to time and budget constraints, other possible participants were not considered. Qualitative interviews were selected for this study because of the need for in-depth information regarding a little studied phenomenon. Qualitative interviews provided rich and usable data that I could collect while pursuing a doctoral degree.

\section{Findings}

Chapter two (Article 1) examines the supports and barriers that influenced the careers of recent hires at the U.S. Fish and Wildlife Service through the lens of the Social Cognitive Career Theory. Twenty two culturally diverse recent hires were interviewed using semistructured, open-ended interviews. Barriers fit into four main thematic categories: financial, institutional, social and familial, and discrimination. Overall, a lack of knowledge of FWS careers was the most mentioned barrier. As a result of lack of knowledge, the majority (19 of 22) of recent hires did not consider a career with the FWS until late in their undergraduate or graduate school careers, or after they had begun their careers. Underrepresented groups perceived more barriers to pursuing a natural resource career. Importantly, underrepresented groups perceived more social barriers than white males. The lack of social and familial support perceived by underrepresented individuals may stem from a lack of family knowledge about the field. Although discrimination did not prevent recent hires from obtaining a job, they perceived age discrimination, gender discrimination, and racial discrimination. Supports to 
career pursuit also fit into four main thematic categories: social support and encouragement, instrumental assistance, role models and mentors, and financial resources. White males and underrepresented individuals emphasized the importance of supervisors (both as instrumental assistance and role models/mentors). Recent hires also discussed the importance of early work experience and paid internships.

Chapter 3 (Article 2) examines the barriers and supports that influenced the degree selection of natural resource undergraduates at West Virginia University and Alabama A\&M University. The supports and barriers that influenced degree choices of 22 undergraduates were examined through the lens of the Social Cognitive Career Theory. This study found four main thematic categories of barriers: financial, institutional, social and familial, and discrimination. Overall, a lack of knowledge of the natural resource field was the most mentioned barrier. As a result of lack of knowledge, the majority (15 of 22) of undergraduates did not consider a natural resource major until after entering their university. Lack of knowledge may also impact the level of familial support for pursuing a natural resource degree. Interestingly, lack of familial support was more commonly perceived by undergraduates from underrepresented groups. Undergraduates from non-traditional backgrounds (city-raised, non-anglers/hunters) also perceived more barriers to pursuing a natural resource career than students from traditional backgrounds. Although discrimination did not prevent the interviewed undergraduates from pursuing a natural resource degree, female undergraduates perceived gender discrimination in the natural resource field. Supports to career pursuit also fit into four main thematic categories: social support and encouragement, instrumental assistance, role models and mentors, and financial resources Undergraduates emphasized the importance of professors (both as instrumental assistance and 
role models/mentors). Undergraduates also discussed the importance of early work experience and paid internships. Finally, undergraduates discussed the importance of the close-knit natural resource program community.

Chapter 4 (Article 3) aims to contribute to research on natural resource career choice by comparing barriers experienced by undergraduates and recent hires. Barriers that influenced the careers of 22 undergraduates and 22 recent hires were compared. The most notable difference between the two groups was that undergraduates experienced increased barriers because of non-traditional backgrounds, whereas recent hires experienced increased barriers because of ethnicity/race. In natural resource degree programs, non-traditional students can be considered an underrepresented group, and therefore may face increased barriers similar to ethnic/racial minorities in non-traditional careers. Overall, a lack of knowledge of the natural resource field was the most mentioned barrier. The lack of knowledge persisted through high school, undergraduate education, graduate school, and even into beginning a career for some young adults. Lack of knowledge may also impact the level of familial support for pursuing a natural resource degree and career, especially for underrepresented groups. Although discrimination did not prevent undergraduates and recent hires from pursuing a degree or career, they perceived discrimination as a student or new professional.

In conclusion, the results emphasized specific barriers were faced by young adults and underrepresented groups pursuing natural resources. The unique barriers perceived by definite groups highlight the need to design recruitment and retention techniques for specific target populations. By carefully designing support systems for young adults and underrepresented 
groups, natural resource organizations can help them overcome barriers and enter the natural resource workforce.

Furthermore, the successful, but limited application of the SCCT to natural resourcerelated career choice indicates potential for future research in this area. It is critical that researchers continue to focus efforts on the barriers to young adults, if the impending human resource crisis is to be alleviated. Future research should include young adults that did not successfully navigate a natural resource career or were unable to overcome barriers. 


\section{References}

Adams, C.E., \& Moreno, M. (1998). A comparative study of natural resource professionals in minority and majority groups in the Southeastern United States. Wildlife Society Bulletin, 26 (4), 971-981.

Ali, S. R., McWhirter, E. H., \& Chronister, K. M. (2005). Self-efficacy and vocational outcome expectations for adolescents of lower socioeconomic status: A pilot study. Journal of Career Assessment, 13, 40-58.

Bandura, A. (1986). Social foundations of thought and action: A social cognitive theory. Englewood Cliffs, NJ: Prentice-Hall.

Bandura, A. (1999). Social cognitive theory of personality. In L. A. Pervin \& O. P. John (Eds.), Handbook of personality: Theory and research (2nd ed., pp. 165-196). New York: Guilford Press.

Betz, N.E. (2008). Advances in vocational theories. In S. Brown \& R. Lent (Eds.), Handbook of Counseling Psychology. New York: Wiley.

Bogdan, R., \& Biklen, S.K. (2003). Qualitative research for education: an introduction to theory and methods ( $4^{\text {th }}$ ed.). Boston: Allyn and Bacon.

Bowman, M.L., \& Shepard, C.L. (1985). Introducing minorities to natural resource career opportunities. Ohio Journal of Science, 85, 29-33.

Brown, M.T. (2000). Blueprint for the assessment of socio-structural influences in career choice and decision making. Journal of Career Assessment, 8, 371-378.

Brown, S.B. (Ed.) (2002). Career choice and development. San Francisco, CA: Jossey-Bass.

Brown, S.D., \& Lent, R.W. (1996). A social cognitive framework for career choice counseling. The Career Development Quarterly, 44, 354-366.

Carnevale, A.P., Strohl, J., \& Melton, M. (2011). What is it worth? The economic values of college majors. Georgetown University Center on Education and the Workforce. Retrieved from http://cew.georgetown.edu/whatsitworth.

Chavez, D.J. (2000). Invite, include, and involve! Racial groups, ethnic groups, and leisure. In M.T. Allison \& I.E. Schneider (Eds.), Diversity and the Recreation Profession: Organizational Perspectives (179-191). State College, PA: Venture Publishing.

Chesney, C.E. (1981). Should racial minorities consider careers in natural resources? Journal of Non-white Concerns, 146-153. 
Conroy, C.A. Reinventing career education and recruitment in agricultural education for the $21^{\text {st }}$ century. Journal of Agricultural Education, 41, 73-84.

Erikson, P.P. (1999). A-whaling we will go: Encounters of knowledge and memory at the Makah Cultural and Research Center. Cultural Anthropology, 14, 556-583.

Flores, L. Y., Navarro, R. L., Smith, J. L., \& Ploszaj, A. M. (2006). Testing a model of nontraditional career choice goals with Mexican American adolescent men. Journal of Career Assessment, 14, 214-234.

Fortmann, L. (1990). The role of professional norms and beliefs in the agency-client relations of natural resource bureaucracies. Natural Resource Journal, 30, 361-380.

Guba, E.G., \& Lincoln, Y.S. (1981). Effective evaluation: improving the usefulness of evaluation results through responsive and naturalistic approaches. San Francisco, CA: Jossey-Bass.

Hackett, G., \& Betz, N.E. (1981). A self-efficacy approach to the career development of women. Journal of Vocational Behavior, 18, 326-336.

Hawley, P. (1972). Perceptions of male models of femininity related to career choice. Journal of Counseling Psychology, 19, 308-313.

Kuzel, A.J., \& Like, R.C. (1991). Standards of trustworthiness for qualitative studies in primary care. In P.G. Norton, M. Stewart, F. Tudiver, M.J. Bass, and E.V. Dunn (eds) Primary Care Research: Traditional and Innovative Approaches. Newbury Park, California: Sage, $138-158$.

Lent, R.W. (2005). A social cognitive view of career development and counseling. In S.D. Brown \& R.W. Lent (Eds.), Career development and counseling: Putting theory and research to work (pp. 101-127). New York: John Wiley.

Lent, R.W., \& Brown, S.D. (2006). On conceptualizing and assessing social cognitive constructs in career research: A measurement guide. Journal of career assessment, 14, $12-35$.

Lent, R.W., Brown, S.D., Brenner, B., Chopra, S.B., Davis, T., Talleyrand, R., \& Suthakaran, V. (2001). The role of contextual supports and barriers in the choice of math/science educational options: A test of social cognitive hypotheses. Journal of Counseling Psychology, 48, 474-483.

Lent, R.W., Brown, S.D., \& Hackett, G. (1994). Toward a unifying social cognitive theory of career and academic interest, choice, and performance. Journal of Vocational Behavior, 45, 79-122. 
Lent, R. W., Brown, S. D., \& Hackett, G. (2000). Contextual supports and barriers to career choice: A social cognitive analysis. Journal of Counseling Psychology, 47, $36-49$.

Lent, R.W., Brown, S.D., \& Hackett, G. (2002) Social cognitive career theory. In D. Brown (Ed.), Career choice and development (Ch. 7). San Francisco, CA: Jossey-Bass.

Lent, R. W., Brown, S. D., Nota, L., \& Soresi, S. (2003). Testing social cognitive interest and choice hypotheses across Holland types in Italian high school students. Journal of Vocational Behavior, 62, 101-118.

Lent, R. W., Brown, S. D., Schmidt, J., Brenner, B., Lyons, H., \& Treistman, D. (2003). Relation of contextual supports and barriers to choice behavior in engineering majors: Test of alternative social cognitive models. Journal of Counseling Psychology, 50, 458-465.

Lent, R.W., Brown, S.D., Talleyrand, R., McPartland, E.B., Davis, T., Chopra, S.B., Alexander, M.S., Sutherakaran, V., \& Chai, M. (2002). Career choice barriers, supports, and coping strategies: College students' experiences. Journal of Vocational Behavior, 60, 61-72.

Lent, R.W., Brown, S.D., Sheu, H., Schmidt, J., Brenner, B.R., Gloster, C.S, et al. (2005). Social cognitive predictors of academic interests and goals in engineering: Utility for women and students at historically Black universities. Journal of Counseling Psychology, 52, 84-92.

Lent, R.W., Sheu, H., \& Gloster, C.S., Wilkons. (2010). Longitudinal test of the social cognitive model of choice in engineering students at historically Black universities. Journal of Vocational Behavior, 76, 387-394.

Lent, R.W., Paixão, M.P., Tomás da Silva, J., \& Leitão, L.M. (2010). Predicting occupational interests and choice aspirations in Portuguese high school students: A test of social cognitive career theory. Journal of Vocational Behavior, 76, 244-251.

Lent, R.W., Lopez, F.G., Sheu, H., \& Lopez, A.M. (2011). Social cognitive predictors of the interests and choices of computing majors: Applicability to underrepresented students. Journal of Vocational Behavior, 78, 184-192.

Matthews, E., \& Tiedeman, D. V. (1964). Attitudes toward career and marriage and the development of lifestyle in young women. Journal of Counseling Psychology, 11, 374-383.

McLaren, D.R. (1999). The History of indigenous peoples and tourism. Cultural Survival, 23 (2). Retrieved from: http://www.culturalsurvival.org/ourpublications/csq/article/thehistory-indigenous-peoples-and-tourism. 
Merriam, S.B., \& Associates. (2002). Qualitative research in practice: examples for discussion and analysis. San Francisco, CA: John Wiley and Sons, Inc.

Minority Outreach Subcommittee. (1998). Executive summary on a nationwide assessment of the status of State Fish and Wildlife Agencies' efforts to research minorities in their education and outreach programs.

Oetting, R. (2008). Effects of supports and barriers on choice intentions and actions of undergraduate pre-medicine students (Doctoral Dissertation). Retrieved from http://search.proquest.com.www.libproxy.wvu.edu/pqdtft/docview/288231663/1342E $\underline{\mathrm{ABD} 72 \mathrm{~B} 5 \mathrm{E} 8 \mathrm{~B} 8 \mathrm{E} 74 / 1 \text { ? accountid}=2837}$

Organization for Tropical Studies. (2007). Advisory Committee for Academic Diversity manual of best practices for recruiting and retaining underrepresented groups in ecology and the environmental sciences. Retrieved from: http://www.obfs.org/assets/docs/human-diversity/manual-bestpractice.pdf

Outley, C.W. (2008). Perceptions of agriculture and natural resource careers among minority students in a national organization. General Technical Report. PSW-GTR-210. Albany, CA: U.S. Department of Agriculture, Forest Service, Pacific Southwest Research Station.

Patton, M.Q. (2002). Qualitative research and evaluation methods ( $3^{\text {rd }}$ ed.). Thousand Oaks, CA: Sage Publication Ltd.

Schelhas, J. (2002). Race, ethnicity, and natural resources in the United States: A Review. Natural Resources Journal, 42, 723-763.

Sharik, T.L., Liliehold, R.J., \& Richardson (2012, March). Factors influencing undergraduate enrollment trends in natural resources. Paper presented at the $9^{\text {th }}$ Biennial Conference on University Education in Natural Resources, Fort Collins, CO.

Stemler, S. (2001). An overview of content analysis. Practical Assessment, Research, and Evaluation, 7. Retrieved from http://PAREonline.net/getvn.asp?v=7\&n=17

Swanson, J. L., Daniels, K. K., \& Tokar, D. M. (1996). Measuring perceptions of careerrelated barriers: The Career Barriers Inventory. Journal of Career Assessment, 4, 219-244.

Swanson, J.L. \& Gore, P.A. (2000). Advances in vocational psychology theory and research. In S.D. Brown and R.W. Lent (Eds.), Handbook of Counseling Psychology ( $3^{\text {rd }}$ ed., 233-269). New York, New York: Wiley. 
Swanson, J.L \& Woitke, M.B. (1997). Theory into practice in career assessment for women: Assessment and interventions regarding perceived career barriers. Journal of Career Assessment, 5, 431-450.

Taylor, D. (2008). Diversity and the Environment: Myth-Making and the Status of Minorities in the Field. Research in Social Problems and Public Policy, 15, 89-148.

U.S. Department of Agriculture Civil Rights Action Team. (1997). Civil rights at the United States Department of Agriculture: A report by the Civil Rights Action Team 6-8.

U.S Department of Commerce Economics and Statistics Administration. (2011). Overview of race and Hispanic origin: 2010. 2010 Census Briefs.

Wettersten, K. B., Guilmino, A., Herrick, C. G., Hunter, P. J., Kim, G. Y., Beecher, T., et al. (2005). Predicting educational and vocational attitudes among rural high school students. Journal of Counseling Psychology, 52, 658-663. 


\title{
CHAPTER TWO: Article 1
}

Barriers and supports to entering a natural resource career:

Perspectives of culturally diverse recent hires

\author{
Kelly Balcarczyk \\ Dave Smaldone \\ Steve Selin
}

(This article was submitted to the Journal of Forestry in December, 2013)

\begin{abstract}
Federal natural resource agencies are facing a human resource crisis. Many natural resource professionals are reaching retirement and attracting young adults to fill vacancies may prove difficult. Therefore, this study contributes to research on natural resource career choice by examining supports and barriers encountered throughout career development. Supports and barriers that influenced the careers of recent hires at the U.S. Fish and Wildlife Service were examined through the lens of the Social Cognitive Career Theory. Twenty-two culturally diverse recent hires were interviewed using semi-structured, open-ended interviews. Recent hire interviews emphasized specific barriers and supports to young adults and young adults in underrepresented groups pursuing natural resources. Differences between barriers and supports perceived by white males and underrepresented groups highlighted the need to design recruitment and retention techniques for specific target populations. By carefully designing support systems for young adults and underrepresented groups, organizations can help them overcome barriers.
\end{abstract}




\section{Management and Policy Implications}

Barriers encountered by recent hires fit into four categories: financial, institutional, social and familial, and discrimination. Lack of knowledge about careers was the most mentioned barrier. Natural resource organizations may want to focus efforts on early and extensive advertisement of career options, which should extend through high school, college, and graduate school. Underrepresented groups perceived more barriers to pursuing a natural resource career. Importantly, underrepresented groups perceived more social barriers. Therefore, natural resource organizations potentially need to educate not only young adults, but also families about career options. In addition, when trying to attract underrepresented groups, natural resource agencies may want to reach out to organizations that focus on underrepresented groups in natural resources. Supports to career pursuit fit into four categories: social support, instrumental assistance, role models and mentors, and financial resources. White males and underrepresented individuals emphasized the importance of supervisors as instrumental assistance and role models. Thus, supervisors in natural resource organizations may benefit from mentorship training opportunities. Recent hires discussed the importance of early work experience and paid internships. Natural resource organizations may be able to increase recruitment by creating innovative ways to provide early field experience, while continuing to offer paid internships and volunteer opportunities.

Keywords: barriers, career choice, recruitment, retention, supports, underrepresented groups 


\section{Introduction}

Government agencies, particularly those charged with managing and protecting the nation's natural resources, are facing a human resource crisis. The Federal workforce is older than Federal workforces of past decades with employees ages 55 and older increasing from $14.9 \%$ in 1998 to $25.8 \%$ in 2010 (Copeland 2011). Not surprisingly, natural resource agencies mirror government-wide statistics with over 40 percent of the workforce over 50 years of age (Copeland 2011; Renewable Resources Foundation 2003). With many career natural resource professionals reaching retirement age, agencies may see a loss of institutional memory and core competencies, such as leadership and science expertise (Minority Outreach Subcommittee 1998; Outley 2008). However, this high rate of near retirement within natural resource agencies also presents an opportunity to hire talented young adults interested in natural resource careers.

Unfortunately, attracting young adults to fill the vacancies left by retiring natural resource employees may prove difficult. Compared to the private sector, careers with the government may be less attractive to young adults because of complicated application and hiring processes, mobility requirements, and lower salaries (Renewable Resources Foundation 2003). Furthermore, although currently on the rise from a recent fall, enrollment in natural resource degree programs has not increased in the past three decades (Sharik 2012), which has resulted in a small and possibly shrinking pool of applicants for natural resource positions. In fact, natural resource majors are some of the least popular majors with less than one half of one percent of all college graduates holding a natural resource degree (Carnevale et al. 2011; Sharik 2012). 
In addition, increasingly, young adults in the recruitment pool depart from the traditional background of current natural resource professionals (rural-raised, land grant University fisheries/wildlife/biology-educated, angler/hunter, white male), and agency workplace culture has not changed to match this new recruitment pool (Minority Outreach Subcommittee 1998). The U.S. Census Bureau projects that by 2050, people of color in this nation will more than double and will comprise the majority of the population (U.S Department of Commerce Economics and Statistics Administration 2011). However, a study on diversity in environmental/natural resource institutions (Taylor 2008) found that approximately one-fourth of 29 government environmental/natural resource agencies and more than one-third of 129 mainstream environmental/natural resource organizations had not hired any minorities in three years preceding the study. Moreover, thirty-five percent of the most widely recognized environmental/natural resource organizations and 19 percent of government agencies indicated that they had no minorities on staff (Taylor 2008). This lack of cultural diversity in the field can only serve to compound the consequences of mass retirement. Studies have shown that culturally diverse workforces serve to increase the number of innovative solutions for environmental problems (Organization for Tropical Studies 2007).

\section{Purpose and Objectives}

The disconnect between the cultural diversity of natural resource agencies and the U.S. population, and the lack of interest in natural resource careers highlight the need to change the recruitment and hiring practices in the field. Natural resource agencies can improve the recruitment and retention of capable professionals from diverse backgrounds through a better understanding of the supports and barriers faced along their career path. Therefore, this study seeks to contribute to empirically-based research on the choice of natural resource careers by 
examining supports and barriers encountered throughout career development. Specifically, this study seeks to answer two main research questions: (1) What supports and barriers influenced a recent hire's decision to pursue a natural resource career?, and (2) How do sociodemographic factors influence perceived supports and barriers?

\section{Theoretical Framework}

Few studies have specifically examined supports and barriers influencing natural resource career choices, with even fewer focusing on career choices of underrepresented groups. Past studies have highlighted various barriers to choosing a natural resource-related career, including lack of natural resource career information (e.g. Adams and Moreno 1998; Bowman and Shepard 1985; Maughan et al. 2001; Outley 2008), discrimination (e.g. Chesney 1981; Washington and Rodney 1986), lack of role models (Organization for Tropical Studies 2007), lack of support from family and friends (Outley 2008), limited funding opportunities (Organization for Tropical Studies, 2007), and general negative perceptions of careers (Chesney 1981; Leatherberry 1988; Outley 2008). Reported supports for pursuing a natural resource-related field were parental support (Washington and Rodney 1986; Wildman and Torres 2001), role models and mentors (Outley 2008), hands-on experience (Bowman and Shepard 1985; Wildman and Torres 2001), financial incentives/support (Outley 2008;

Wildman and Torres 2001), and availability of jobs (Conroy 2000; Esters 2007).

Unfortunately, most of these past studies have lacked theoretical underpinnings needed to expand hypothesis testing and understanding.

The Social Cognitive Career Theory (SCCT) offers a useful framework for examining factors influencing natural resource career choice of diverse individuals (Lent et al. 2000). The SCCT is suitable for this study because it examines the individual's career development within 
his or her cultural and environmental context, while also considering personal agency in the choice process. The SCCT incorporates three central social cognitive variables (self-efficacy, outcome expectations, and personal goals) from the social cognitive theory (Bandura 1986) and includes interests as an additional building block of career development (Lent et al. 1994; Lent et al. 2002). More importantly for this study, the SCCT recognizes that social cognitive variables are not solely responsible for shaping career outcomes by highlighting important person (e.g. ethnicity, gender) and contextual variables (supports, barriers) (Lent et al. 1994; Lent et al. 2002).

The core social cognitive and contextual variables represent the set of influences that are particularly important during the active phases of career decision making (Lent and Brown 2006, Figure 1). Supports and barriers along the career path can help to shape learning processes/experiences that determine interests in and choice of natural resource careers (Lent et al. 1994; Lent and Brown 2006). In addition, supports and barriers are the building blocks of real and perceived opportunity structure within which career plans are devised and implemented (Lent et al. 1994). Notably, the perception of supports and barriers throughout the career path is highly influenced by person factors (e.g. gender, ethnicity), which is of particular interest in this study (Lent et al., 1994; Lent et al., 2000).

\section{Methodology}

This study employed a basic interpretive qualitative research design (Patton 2002). A qualitative research design was best suited to provide insight into natural resource career choice because it: 1) seeks to understand experiences and meanings people make of experiences, 2) studies a person in the context of their interpersonal environment, and 3) 
explores a little researched phenomenon for which standardized instruments have not been developed (Patton 2002).

\section{Sample Selection}

The goal for sample selection was to specifically identify participants who would contribute valuable insight about natural resource career paths. Therefore, we purposefully sampled recent hires at the U.S. Fish and Wildlife Service (FWS) using criterion sampling. Participants were selected based on the following criteria: 1) FWS full-time, permanent employee, 2) between 18 and 30 years of age, 3) hired by the FWS within the past 3 years, and 4) socio-demographic factors (race and gender).

Initial participants were recommended by FWS managers from all regions. Each initial participant was asked to recommend three additional recent hires that fit the research criteria. This snowball sampling technique was used until reaching theoretical saturation (when recent hire interviews revealed no new or relevant themes; Thomson 2011).

\section{Data Collection}

Semi-structured, open-ended interviews (Newman and Benz 1998) were conducted via Skype from November 2012 - June 2013. Questions derived from previous SCCT research (questions 2-4, Appendix B) on supports and barriers (e.g. Lent et al. 2002; Diaz 2010;

Hosoi 2010; Wicker 2008) were included in an interview guide, ensuring that the same lines of inquiry were pursued with each participant. However, the interviewer was free to probe and ask further questions. Pilot interviews were used to refine the interview guide and style, as well as to determine additional questions. Skype interviews lasted 25 - 80 minutes and were recorded using MP3 Skype recorder. The interview consisted of 11 main questions with 3 of those being used in this study 


\section{Data Analysis}

Recorded interviews were transcribed verbatim and checked line-by-line. Data were hand-coded and divided into meaningful analytical units using NVivo 10. Content-analysis using a mix of a priori and emergent coding techniques was used to ensure exhaustiveness of the analysis (Stemler 2001). A priori criteria was derived from SCCT theoretical background to include themes (e.g. financial barriers) already cited as important in the literature. After a priori coding was applied, data were reanalyzed to allow additional themes and sub-themes to emerge (e.g. lack of family knowledge). Coding units were defined as recording units or ideas belonging to only one category (Stemler 2001). To ensure credibility and accuracy of the research findings, preliminary findings were reported back to select participants for review. In addition, all members of the research team reviewed and agreed upon coding schemes.

\section{Results}

\section{Demographics}

Twenty-two FWS recent hires representing eight of nine FWS regions were interviewed (regions 2 -9). Culturally diverse recent hires with 3 or less years of service contributed to the findings of this study (Table 1).

\section{Barriers}

Recent hires encountered a wide range of barriers to obtaining a career with the FWS. All of the barriers discussed fit into four main thematic categories: institutional, financial, familial and social, and discrimination. In general, recent hires in underrepresented groups (females, and ethnic and racial minorities) perceived more barriers throughout their job pursuit than white males (Figure 2). 


\section{$\underline{\text { Financial Barriers }}$}

Both white males and underrepresented groups perceived financial barriers to their job pursuit. The most common financial barrier was moving costs ( 5 recent hires; Figure 2). Underrepresented groups perceived more financial barriers than white males. Additional financial barriers faced by underrepresented groups were: (1) needing to take a paid internship, (2) low pay, and (3) lack of loan repayment plans. The low pay (compared to other organizations) may be more of a barrier to underrepresented individuals that work in urban offices. A black female discussed pay not matching the cost of living:

For a while, I was still being paid my intern salary while starting my full-time position and it was indeed a financial barrier for quite a while. I was not able to afford an apartment here in the Washington DC metro area and so I rented rooms off of craigslist. And there's whole other safety concern that goes along with that...

\section{$\underline{\text { Institutional Barriers }}$}

Institutional barriers (school and work related barriers) were the most commonly mentioned barriers by recent hires, with lack of knowledge about FWS jobs being most common (14 recent hires). Competitive hiring practices (13 recent hires) and lack of required courses to meet job descriptions (11 recent hires) were also commonly mentioned barriers. A white female discussed her lack of knowledge about FWS jobs:

Before my internship, I had honestly never heard of the Fish and Wildlife Service. I didn't know that that the service existed, and it was located like 45 minutes from my house. So it's just a basic lack of awareness of: 1. our refuge being right here and 2 . understanding the mission of the service... and that there are opportunities available for recent graduates or even students still in college. I just wasn't aware while I was in school, both high school and undergrad.

White male individuals perceived two unique institutional barriers: veteran's preference and disparity between wage grade and GS positions. One white male discussed the barrier of wage grade vs. GS positions as: 
The biggest one is the Fish and Wildlife Service's lack of looking at wage grade as equals, instead of on a different level as GS. You know having a biology degree is important to a biologist. But for running a half million-dollar machine that builds roads and doing million-dollar projects, you don't need to have that. It's a different skill set... Not every position in the field needs to be filled by a biologist...

Underrepresented groups perceived unique institutional barriers as well. Institutional barriers perceived by underrepresented groups were (1) university was not aware of FWS programs, (2) FWS structure (barriers related to the way the FWS is organized and managed; i.e. being a top heavy bureau), (3) relocation requirements, and (4) lack of skills. A white female discussed universities not being aware of FWS programs:

The biggest thing was people not really knowing what exactly was going on ... it would also be really helpful if the colleges were more aware of the program as well... The pathways program--I think that would be a humongous help.

\section{$\underline{\text { Familial and Social Barriers }}$}

Underrepresented groups perceived more social and familial barriers throughout their job pursuit than white males (Figure 2). However, white males and underrepresented groups both experienced being discouraged from the natural resource field ( 3 recent hires). For example, a white male described being discouraged by a high school guidance counselor, "I do remember high school counselor telling me that I would never get a job in fish and wildlife or with in any type of state or federal agency. 'The jobs are too hard to come by,' she said. I'll never get a job."

The three most common familial and social barriers perceived by underrepresented individuals are cultural dissonance (5 recent hires; all females), lack of work/life balance (4 recent hires), and lack of family knowledge of the field. Some relevant examples of these barriers included: 
So there were always questions about why... Because when you're not home, it's makes everyone else at home feel like they don't know what you're doing, and that you may not be safe... and also financially you are not contributing to the family because you're gone. So it can be a safety issue, a cultural issue, and the financial stability issue.

- black female discussing cultural dissonance

How do you make yourself a successful career person within the Fish and Wildlife Service, but also have a thriving personal life and personal relationships...especially if the people that you live with can't move with you because of their career?... I think that for me has been the biggest thing that has made my family and friends not necessarily like my job.

- bi-racial female discussing lack of work/life balance

My parents are from the Philippines and they don't have the same kind of values when it comes to the environment and conservation...They don't even have the words in my mother's native language to describe what I do... Almost right after I accepted my job with the service, my mom started sending me applications for other jobs because she didn't think that this was a viable career option.

- Hispanic/Asian male discussing lack of family knowledge

$\underline{\text { Discrimination }}$

Individuals from both groups (white males and underrepresented groups) perceived various types of discrimination along their job pursuit (Figure 2). Discrimination did not prevent recent hires from getting a job, but many recent hires felt discrimination in the workforce. Individuals from both groups experienced age discrimination. A white female said:

I did run into where coworkers... didn't respect the ideas that I had, nor thought that I was qualified for the position. Things like that... I do wonder if it was age...I had been in this position already, but being 20 years younger than someone... and being 20 years younger and a female...

Half of the white males perceived reverse discrimination ( 3 of 6 white males). They felt that diversity initiatives made it more difficult to obtain a job. One white male described this barrier: 
It's like a lot of things...the service gets all up in arms that we don't have enough minorities...I'm not saying like we don't need diversity in the agency or veterans aren't owed a debt for their service, but it really bothers me that they do the names on applications. It should be a Social Security number on your resume. People should only be hired based on their experience and their abilities, not what demographic they fill.

Individuals from underrepresented groups also perceived discrimination based on gender ( 5 recent hires) and race ( 2 recent hires). A black female described perceived discrimination based on both gender and age while working for the service:

When I'm in a room or in at meeting, I tend to be in the minority ... I am a black female... So when I started, I'd have white males who are in the 45 to 65 age range asking me what I'm doing and how long I've been doing this. And it kind of makes me feel like what I'm doing isn't legitimate. I don't know if I am being oversensitive, but it just makes you wonder: Why do I get the questions and others don't?

\section{Supports}

Recent hires also encountered a wide range of supports to obtaining a job. All supports fit into four main categories: instrumental assistance, financial, familial and social, and role models/mentors (Figure 3).

\section{$\underline{\text { Financial Supports }}$}

Both white males and underrepresented groups had financial supports during their job pursuit. The most common financial supports were scholarships (12 recent hires), paid internships (11 recent hires), and graduate stipends (4 recent hires; Figure 3). One white male also received the GI bill and a white female received spousal financial support.

Instrumental Assistance

White males and underrepresented groups perceived instrumental assistance (critical school or work related support) during their job pursuit. Early work experience was seen as essential by 15 recent hires (Figure 3). In 13 cases, recent hires saw supervisor guidance and 
support as essential to them obtaining a job. For example, a white male described the role his supervisor played:

Like I said my immediate supervisor...He is the one that took personal interest and got things to happen on a higher level...He forced things to get done and go through... Actually without him I would not have the job. It really boils down to one person. Individuals in underrepresented groups perceived more instrumental supports than white males (Figure 3). Most commonly, underrepresented groups were supported by university career guidance programs (8 recent hires), professional development/courses (6 recent hires), and professional networks (3 recent hires). A white female described professional networks as a support:

Being able to kind of make connections with those agency employees; that really helped me to take a look at other options... Having them out there also looking for positions really helped me find that job. They just always were giving me hints about how to tweak my resume, or how to better be competitive on the applications, and just the skills that I needed...

\section{$\underline{\text { Social or Familial Support }}$}

Family support was the number one social support discussed by recent hires $(21$ recent hires), followed by friends ( 9 recent hires), and outdoor upbringing ( 8 recent hires; Figure 3 ). A white male discussed his outdoor upbringing:

Hunting and fishing was definitely a pastime. My grandpa used to take me fishing in Canada as a kid, when I was 12 or 13 years old...taking me up there and taking me all these places. And college... a lot of times hang out those folks going hunting, fishing, photography, those types of things...learning how to do them.

Individuals from underrepresented groups perceived more social and familial supports than white male individuals, including minority professional organizations (3 recent hires), school cohorts (2 recent hires), and spouses ( 2 recent hires). A black female described the support of a minority professional organization: 
I am referring to a minority organization. And the reason why that is important is because again the type of the field that I chose is very heavy on the white male side...So academic minority organizations that are geared towards natural resources, that's another source of supports. Those were really, really important to me personally because it was...people from different cultures who were pursuing the same thing that I was pursuing.

\section{Role Models and Mentors}

Supervisors were the most commonly mentioned role model/mentor for recent hires

(15 recent hires). Parents (5 recent hires) and local natural resource professionals (3 recent hires) also acted as mentors and role models for both white males and underrepresented individuals. Recent hires also viewed high school teachers, internship program mentors, coworkers, graduate advisors, alumni, and other family members as role models and mentors. A biracial female described the role of her supervisor:

And she is one of the reasons that I was inspired to be in the career...because she was so good at her job. But it was also because she saw talent in me and told me, "this is a career that you should consider going into." She is one of the more influential people for me...

A white male also described the role a natural resource professional played in his career:

The person that got me into wildlife was a local private land biologist that I ended up being forced into working with in a high school English assignment. I had to interview someone...So I picked somebody in the field. Oddly enough 15-20 years later, I'm still good friends with the guy...So it's those kind of lucky mentors that you happen to catch or meet up in your life.

\section{Discussion and Recommendations}

Similar to a study by Lent et al. (2002) examining barriers in math and sciences, this study found four main thematic categories of barriers: financial, institutional, social and familial, and discrimination (Betz 2008). Overall, a lack of knowledge of FWS careers was the most mentioned barrier, which is consistent with past research findings on natural resourcerelated careers (Adams and Moreno 1998; Bowman and Shepard 1985; Maughan et al. 2001; 
Outley 2008). As a result of lack of knowledge, the majority (19 of 22) of recent hires did not consider a career with the FWS until late in their undergraduate or graduate school careers, or after they had begun their careers. Therefore, the FWS and other natural resource organizations may want to focus efforts on early and extensive advertisement of career options, which should extend through high school, college, and graduate school. Starting in high school, career pathways could be created to guide students through natural resource career development. In addition, agency environmental education programs could include information on potential career and internships opportunities to ensure students of all ages are exposed to these options.

Underrepresented groups perceived more barriers to pursuing a natural resource career, similar to past SCCT research on non-traditional careers (Luzzo and McWhiter 2001). In addition, ethnic minorities have been found to have significantly lower coping-efficacy (belief they can overcome barriers) than Caucasians (Lent et al. 2005). Consequently, the FWS and other natural resource organizations may need to use specialized recruitment and retention techniques for underrepresented groups. For example, careers and programs could be advertised to minority-serving universities and urban high schools to address the lack of knowledge and professional support barriers. Additionally, special early work experiences as well as scholarships and stipends could be offered to underrepresented groups to help overcome the more commonly mentioned financial barriers.

Importantly, underrepresented groups perceived more social barriers than white males. The lack of social and familial support perceived by underrepresented individuals may stem from a lack of family knowledge about the field. Therefore, the FWS and other natural resource organizations potentially need to educate not only young adults, but also families 
about career options and pathways. Interestingly, underrepresented groups also perceived social supports as more important in their career pursuit and in overcoming barriers than white males. Ethnic groups with traditional collectivist values (e.g. Mexican Americans), individuals in more isolated communities (e.g. rural Appalachia), and women often emphasize the support of family in academic and career decision making (Ali and Saunders 2006; Flores and O'Brien 2002; Tang et al. 1999; Wetterson et al. 2005). Social supports have also been shown to neutralize impacts of barriers along the academic or career path of women and ethnic minorities (Lent et al. 2011; Quimby and O’Brien 2004). Thus, when trying to attract underrepresented groups, the FWS and other natural resource agencies may want to reach out to organizations and social groups that focus on underrepresented groups in natural resources, such as Minorities in Agriculture and Natural Resource Related Sciences. Additionally, moving requirements may be a greater barrier to underrepresented groups (family-oriented cultural groups, and women seeking to start a family) that more commonly rely on family, friends, and social networks. Flexibility in the moving requirements may help attract and retain more young adults in underrepresented groups.

Although discrimination did not prevent recent hires from obtaining a job, they perceived age discrimination, gender discrimination, and racial discrimination. Unfortunately, due to time and funding constraints this study was not able to interview young adults that did not enter the natural resource field, but past studies have found that discrimination has prevented young adults from entering natural resource careers (e.g. Chesney 1981; Washington and Rodney 1986). For the FWS, discrimination may be a factor that impacts young adult retention rather than recruitment. Therefore, training focused on effective cultural 
and generational communication techniques given at all levels of employment throughout the organization could help boost retention.

Supports to career pursuit also fit into four main thematic categories: social support and encouragement, instrumental assistance, role models and mentors, and financial resources (Lent et al. 2002; Betz 2008). White males and underrepresented individuals emphasized the importance of supervisors (both as instrumental assistance and role models/mentors). Role models have been considered to be a support to natural resource-related career pursuit in the past (Outley, 2008). In addition, role models have been shown to be more influential on women, ethnic minorities, and students with lower socio-economic status (Gushue and Whitson, 2006; Kenny et al., 2007). Given the importance of supervisors as role models, supervisors in the FWS and other natural resource organizations may benefit from mentorship training opportunities. Supervisors could also be connected with a young adult early in their undergraduate career to provide them with course and career guidance.

Recent hires discussed the importance of early work experience and paid internships, both of which were found to be important in past studies (Bowman and Shepard 1985; Wildman and Torres 2001). The FWS and other natural resource organizations may be able to increase recruitment by creating innovative ways to provide early field experience to young adults, while continuing to offer paid internships and volunteer opportunities. Strategies could include working with universities to create field courses or offering service learning course options to diverse disciplines, such as communication or construction management. Focusing early experience efforts on other disciplines and diverse skill sets may help to attract more culturally diverse candidates. 


\section{Conclusion}

Recent hire interviews emphasized specific barriers to young adults, especially in underrepresented groups pursuing natural resources. The difference between barriers and supports perceived by white males and underrepresented groups highlights the need to design recruitment and retention techniques for specific target populations. By carefully designing support systems for young adults and underrepresented groups, natural resource organizations can help them overcome barriers and enter the natural resource workforce.

The successful, but limited application of the SCCT to natural resource-related career choice indicates the promise and potential for future research in this area. It is critical that researchers and managers continue to focus efforts on the supports and barriers to young adults, if the impending human resource crisis is to be alleviated. Future research should include young adults that have successfully navigated the natural resource career path, as well as young adults that did not. Research on young adults not in the field would also further understanding of the barriers to natural resource careers. 


\section{Figures}

Figure 1. Social Cognitive Career Theory Model

The SCCT model of person, contextual, and experiential factors affecting careerrelated choice behavior. Variables in shaded boxes represent the core/proximal social cognitive and contextual variables. Note that the directional arrows in the framework illustrate what are believed to be the predominant causal pathways; however, based on the triadic casual view, the elements influence one another bi-directionally (Lent et al, 1994). Source. Lent and Brown (2006).

Figure 2. Barriers to a Natural Resource Career

Barriers perceived by U.S. Fish and Wildlife Service recent hires. Numbers represent the number of recent hires that discussed each of the themes. The four main thematic categories of barriers were: institutional (red), financial (green), familial and social (purple), and discrimination (dark blue).

Figure 3. Supports to a Natural Resource Career Supports perceived by U.S Fish and Wildlife Service recent hires. Numbers represent the number of recent hires that discussed each of the themes. Thematic categories are: instrumental assistance (red), financial (green), familial and social (purple), and role models/mentors (dark blue).

\section{Tables}

Table 1. Demographic data of 22 U.S. Fish and Wildlife Service's recent hires. 


\section{References}

Adams, C.E., and M. Moreno. 1998. A comparative study of natural resource professionals in minority and majority groups in the Southeastern United States. Wildlife Soc B.(4): 971-981.

Ali, S. R., and J.L. Saunders. 2006. College expectations of rural Appalachian youth: An exploration of social cognitive career theory factors. Career Dev Q. 55: 38-52.

Bandura, A. (1986). Social foundations of thought and action: A social cognitive theory. Prentice-Hall, Englewood Cliffs, NJ. 617p.

Betz, N.E. 2008. Advances in vocational theories. P. 357-374 in Handbook Of Counseling Psychology. S. Brown and R. Lent (eds.). Wiley, New York, NY.

Bowman, M.L., and C.L. Shepard. 1985. Introducing minorities to natural resource career opportunities. Ohio J Sci. 85, 29-33.

Carnevale, A.P., J. Strohl, and M. Melton. 2011. What is it worth? The economic values of college majors. Available online at http://cew.georgetown.edu/whatsitworth; last accessed Sept. 9, 2013.

Chesney, C.E. 1981. Should racial minorities consider careers in natural resources? J Nonwhite Con. 41(4): 146-153.

Conroy, C.A. 2000. Reinventing career education and recruitment in agricultural education for the $21^{\text {st }}$ century. J Agr Educ. 41: 73-84.

Copeland, C.W. 2011. The federal workforce: Characteristics and trends. Con. Res. Serv. Tech. Rep. RL34685. 28p.

Diaz, W. 2010. Relationship of perceived barriers to career self-efficacy among Latino undergraduates at a New England regional public university. Ph.D. dissertation, Johnson \& Wales Univ., Providence, Rhode Island. 164p.

Esters, L.T. 2007. Factors influencing postsecondary education enrollment behaviors of urban agricultural education students. Career Tech Ed Res. 32: 79-98.

Flores, L. Y., and K.M O’Brien. 2002. The career development of Mexican American adolescent women: A test of social cognitive career theory. J Couns Psychol. 49: 14-27.

Gushue, G. V., and M.L. Whitson. 2006. The relationship among support, ethnic identity, career decision self-efficacy, and outcome expectations in Africa American high school students. J Career Dev. 33: 112-124. 
Hosoi, S.A. 2010. Culture matters: Factors affecting the persistence of European American and Asian women in two U.S. engineering doctoral programs. Ph.D. Dissertation, Colorado State Univ., Fort Collins, CO. 146p.

Kenny, M. E., L. Gualdron, D. Scanlon, E. Sparks, D.L. Blustein, and M. Jernigan. 2007. Urban adolescents' constructions of supports and barriers to educational and career attainment. J Couns Psychol. 54: 336-343.

Leatherberry, E.C. 1988. Black high school students' images of forestry as a profession. $J$ Negro Educ, 57: 208-219.

Lent, R.W. 2005. A social cognitive view of career development and counseling. P. 101-237 in Career development and counseling: Putting theory and research to work. S.D. Brown and R.W. Lent (eds.). Wiley, New York, NY.

Lent, R.W., and S.D. Brown. 2006. On conceptualizing and assessing social cognitive constructs in career research: A measurement guide. J Career Assessment. 14: 12-35.

Lent, R.W., S.D. Brown, and G. Hackett. 1994. Toward a unifying social cognitive theory of career and academic interest, choice, and performance. J Vocat Behav. 45:79-122.

Lent, R. W., S.D. Brown, and G. Hackett. 2000. Contextual supports and barriers to career choice: A social cognitive analysis. J Counsel Psychol. 47: 36-49.

Lent, R.W., S.D. Brown, R. Talleyrand, E.B. McPartland, T. Davis, S.B. Chopra, M.S. Alexander, V. Sutherakaran, and M. Chai. 2002. Career choice barriers, supports, and coping strategies: College students' experiences. J Vocat Behav. 60: 61-72.

Lent, R.W., S.D. Brown, H. Sheu, J. Schmidt, B.R. Brenner, C.S. Gloster, and et al. (2005). Social cognitive predictors of academic interests and goals in engineering: Utility for women and students at historically Black universities. J Counsel Psychol. 52: 84-92.

Lent, R.W., F.G. Lopez, H. Sheu, and A.M. Lopez. 2011. Social cognitive predictors of the interests and choices of computing majors: Applicability to underrepresented students. $J$ Vocat Behav. 78: 184-192.

Luzzo, D. A., and E.H. McWhirter. 2001. Sex and ethnic differences in the perception of educational and career-related barriers and levels of coping efficacy. $J$ Couns Dev. 79: 61-67. Maughan, O.E., D.L. Bounds, S.M. Morales, and S.V. Villega. 2001. A successful educational program for minority students in natural resources. Wildlife Soc Bul. 29: 917-928.

Minority Outreach Subcommittee. 1998. Executive summary on a nationwide assessment of the status of State Fish and Wildlife Agencies' efforts to research minorities in their education and outreach programs. U.S. Fish and Wildlife. Available online at http://www.funoutdoors.com/files/Minority\%200utreach\%20Subcommittee\%20Report.pdf; last accessed Sept. 9, 2013. 
Newman, I., and C.R. Benz. 1998. Qualitative-quantitative research methodology. Exploring the interactive continuum. Southern Illinois University Press, Carbondale and Edwardsville, IL. 240p.

Organization for Tropical Studies. (2007). Advisory Committee for Academic Diversity manual of best practices for recruiting and retaining underrepresented groups in ecology and the environmental sciences. Found online at http://www.obfs.org/assets/docs/humandiversity/manual-bestpractice.pdf; last accessed Sept. 92013.

Outley, C.W. 2008. Perceptions of agriculture and natural resource careers among minority students in a national organization. USDA For. Serv. Gen. Tech. Rep. PSW-GTR-210. 15p. Patton, M.Q. 2002. Qualitative research and evaluation methods ( $3^{\text {rd }}$ ed.). Sage Publication Ltd.. Thousand Oaks, CA. 598p.

Quimby, J. L., and K.M. O’Brien. 2004. Predictors of student and career decision making self-efficacy among nontraditional college women. Career Dev Q. 52: 323-339.

Renewable Resources Foundation. 2003. Federal natural resources agencies confront an aging workforce and challenges to their future roles. Renew Res Jour. 21 (4): 1-32.

Sharik, T.L., R.J. Liliehold, and Richardson. Factors influencing undergraduate enrollment trends in natural resources. Paper, $9^{\text {th }}$ Biennial Conference on University Education in Natural Resources, Fort Collins, CO., March 22, 2012.

Stemler, S. 2001. An overview of content analysis. Practical Assessment, Research, and Evaluation, 7. Available online at http://PAREonline.net/getvn.asp?v=7\&n=17; last accessed Sept. 9, 2013.

Tang, M., N.A. Fouad, and P.L. Smith. 1999. Asian American's career choices: A path model to examine factors influencing their career choices. J Vocat Behav. 54: 142-157.

Taylor, D. 2008. Diversity and the Environment: Myth-Making and the Status of Minorities in the Field. Res Soc Probl Public Pol. 15: 89-148.

Thomson, S.B. 2011. Sample size and grounded theory. J Admin and Govern. 5: 45-52. Washington, W.J. and H.E. Rodney. 1986. How do students learn about natural-resource careers? J Forest. 81: 22-24.

U.S Department of Commerce Economics and Statistics Administration. 2011. Overview of race and Hispanic origin: 2010. 2010 Census Briefs. U.S. Census Bureau Tech. Rep. 24p.

Wettersten, K. B., A. Guilmino, C.G. Herrick, P.J. Hunter, G.Y. Kim, T. Beecher, and et al. 2005. Predicting educational and vocational attitudes among rural high school students. J Counsel Psychol. 52: 658-663. 
Wicker, I. 2008. African American women athletics administrators: pathway to leadership positions in the NCAA a qualitative analysis. Ph.D. Dissertation, North Carolina State University, Raleigh, NC. 150p.

Wildman, M., and R.M. Torres. 2001. Factors identified when selecting a major in agriculture. J Agr Educ. 42 (2): 46-55. 
Figure 1. Social Cognitive Career Theory Model

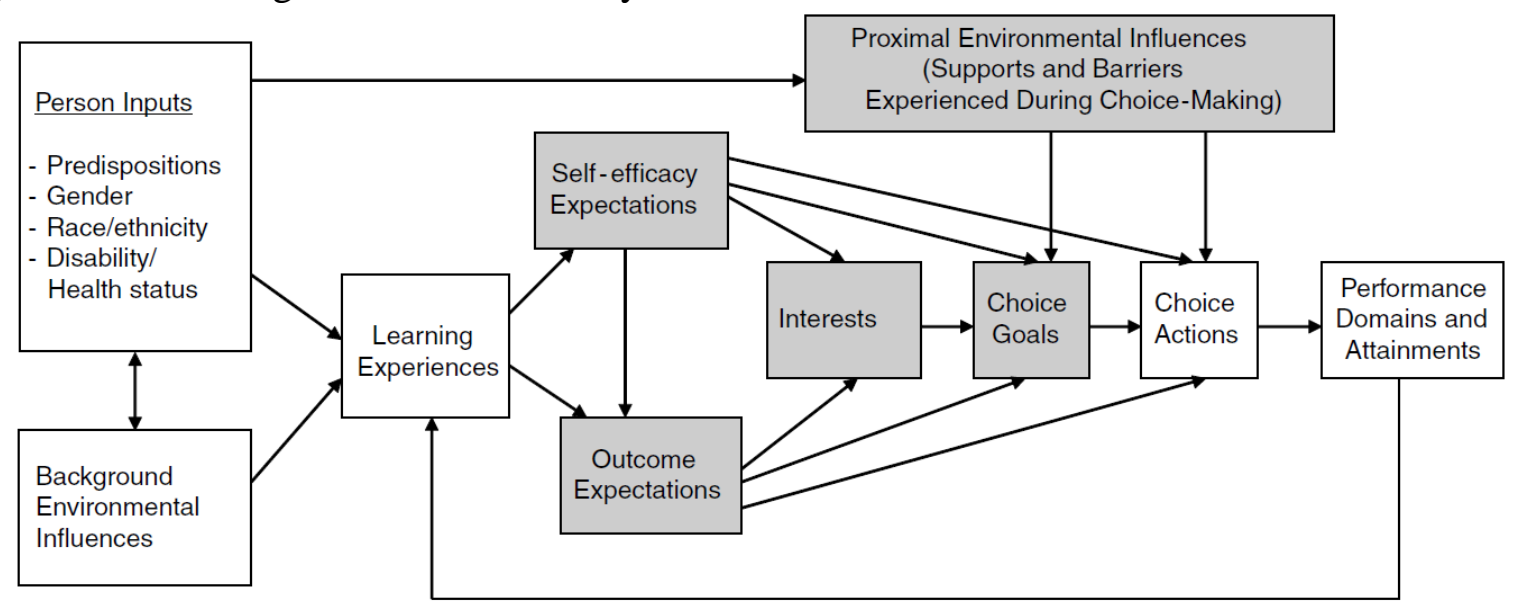


Table 1. Demographic data of 22 U.S. Fish and Wildlife Service's recent hires.

\begin{tabular}{ccc|ccc}
\hline \multirow{2}{*}{ Gender } & & $\begin{array}{c}\text { \# of Recent } \\
\text { Hires }\end{array}$ & & $\begin{array}{c}\text { \# of Recent } \\
\text { Hires }\end{array}$ \\
\hline \multirow{3}{*}{ Race/Ethnicity } & Female & 14 & Region & 2 & 4 \\
& & 8 & 3 & 2 \\
& White & 17 & 4 & 2 \\
& Black & 2 & 5 & 5 \\
& Hispanic/Latino & 1 & 6 & 3 \\
& Hispanic/Asian & 1 & 7 & 1 \\
& Black/White & 1 & 8 & 1 \\
Education Level & Associates & 2 & Year of Employment & 2009 & 2 \\
& Bachelors & 5 & 2010 & 7 \\
& Masters & 13 & 2011 & 6 \\
& Juris Doctor & 2 & 2012 & 6 \\
& & & 2013 & 1 \\
\hline
\end{tabular}


Figure 2. Barriers to Natural Resource Careers

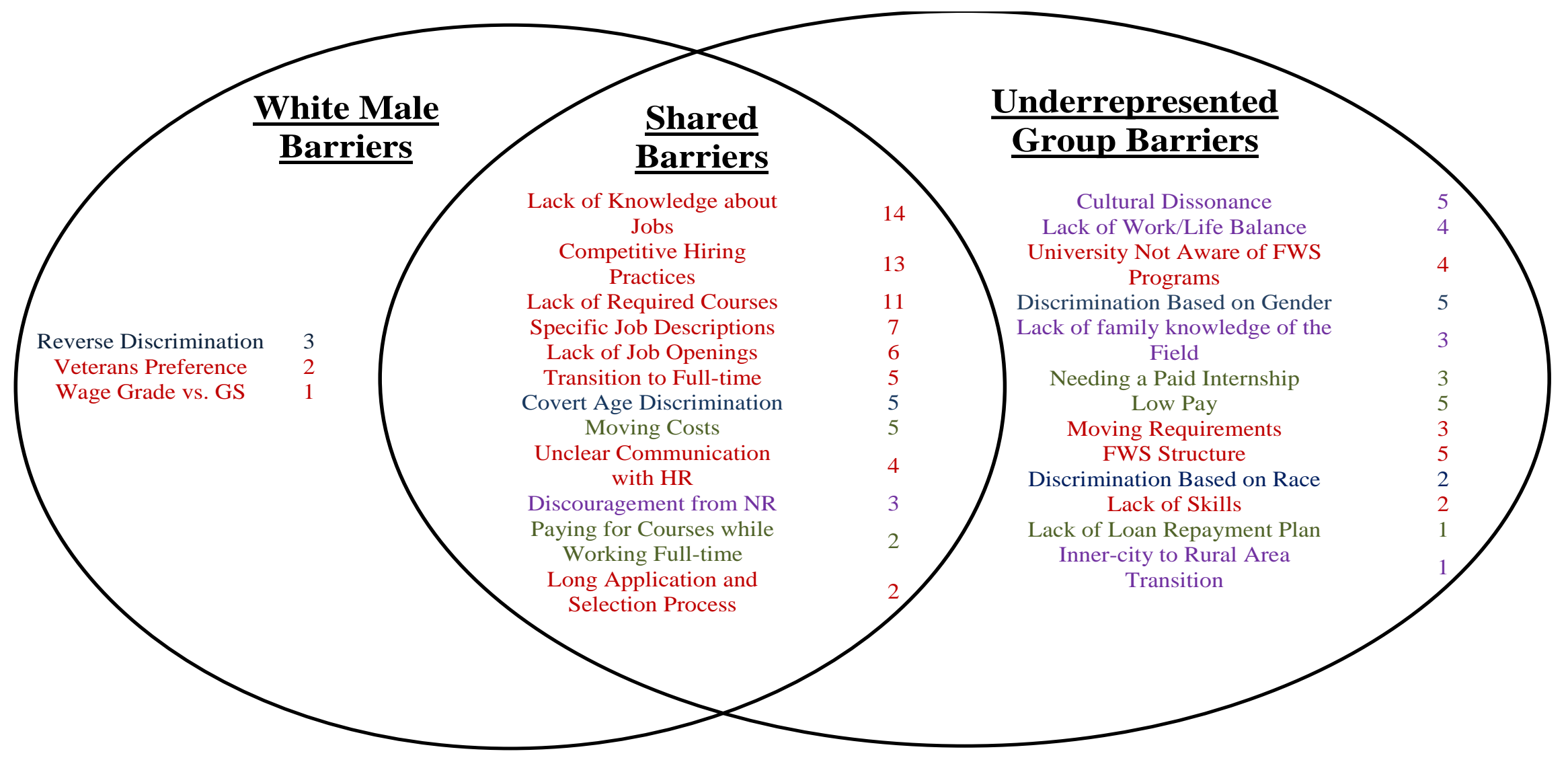


Figure 3. Supports to Natural Resource Careers

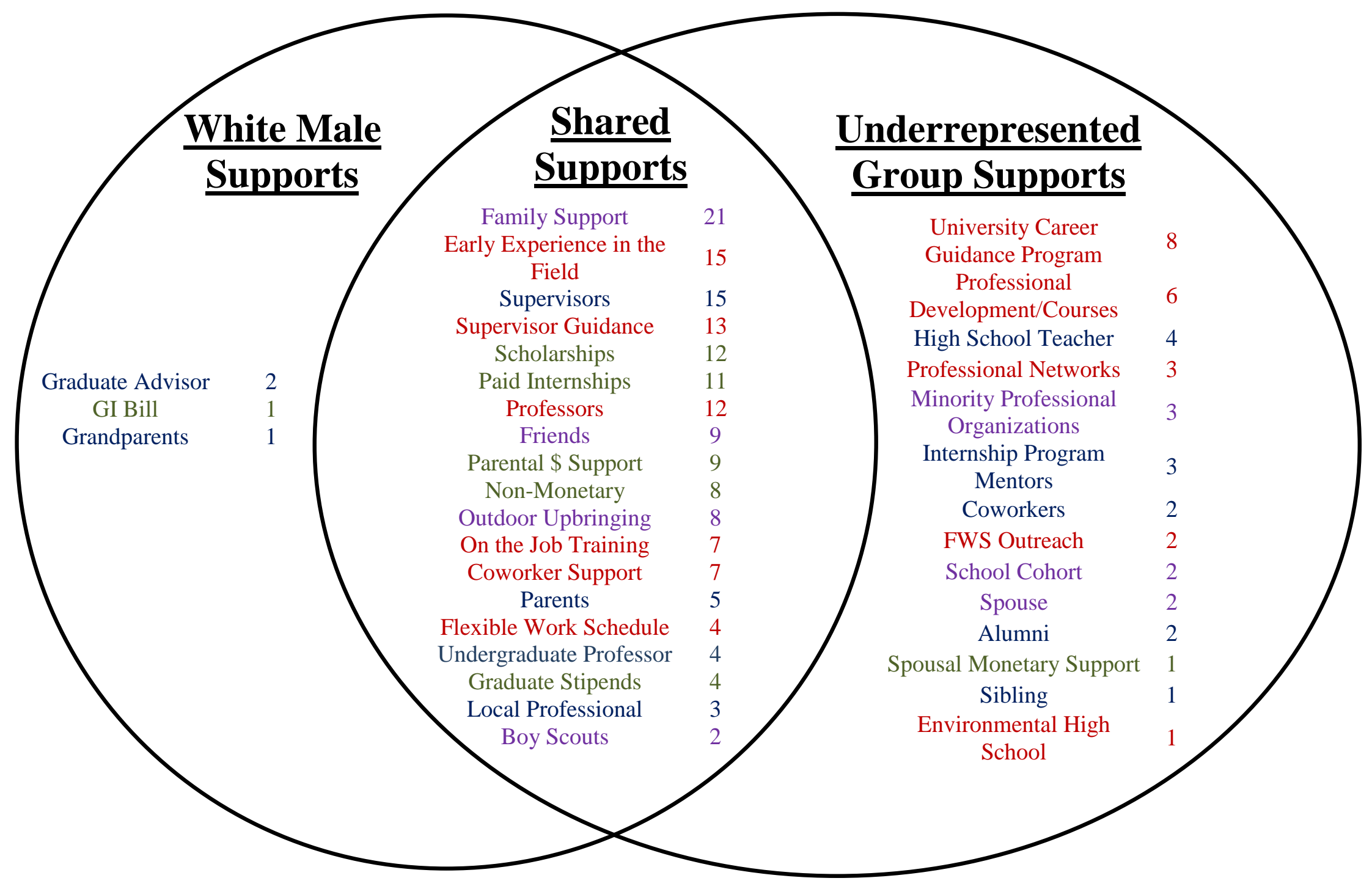


CHAPTER 3: Article 2

\title{
Barriers and Supports to Pursuing a Natural Resource Degree
}

\author{
Kelly Balcarczyk \\ Dave Smaldone \\ Steve Selin
}

(This article was submitted to the Journal of Forestry Special Issue on Education in March, 2014)

\begin{abstract}
Natural resource professions are facing two problems: a paucity of young adults entering the natural resource field and a lack of cultural diversity in the field. Enrollment in natural resource degree programs has not increased overall in the past three decades, which has resulted in a small and possibly shrinking pool of applicants for positions. One reason for dismal enrollment numbers may be lopsided demographics typically found in these programs. Therefore, this study aims to contribute to research on natural resource degree choice by examining supports and barriers encountered while pursuing a natural resource degree. Supports and barriers that influenced degrees choices of 22 culturally diverse undergraduates were examined through the lens of the Social Cognitive Career Theory using semi-structured, openended interviews. Differences between barriers and supports perceived by undergraduates and underrepresented highlighted the need to design recruitment and retention techniques for specific target populations. Techniques to help students overcome barriers are provided.
\end{abstract}

\section{Management and Policy Implications}

Barriers encountered by undergraduates fit into four categories: financial, institutional, social and familial, and discrimination. Lack of knowledge about majors resulted in 15 of 22 students not selecting a natural resource major until after starting at the university. Lack of 
knowledge about the major also often led to parental pressure to select a non-natural resource major, especially in underrepresented groups. Therefore, extensive advertisement on natural resource degrees extending from high school into undergraduate studies is essential. Additionally, families need to be thoroughly educated about career options. Non-traditional students (city-raised, non-hunters/anglers) perceived more social, institutional, and discrimination-type barriers, which stemmed from an unfamiliarity with vocabulary and handson activities. Therefore, natural resource programs may want to offer an optional, short, summer course prior to freshmen year to orient students to basic natural resource practices. Female undergraduates perceived gender discrimination as a barrier, and may need additional mentoring. Supports to degree pursuit fit into four categories: social support, instrumental assistance, role models and mentors, and financial resources. Undergraduates emphasized the importance of professors, early work experience, and the tight-knit student community. Therefore, natural resource programs may want to emphasize opportunities for early work experience and the tightknit community to prospective students, especially underrepresented groups.

Keywords: barriers, recruitment, retention, supports, underrepresented groups

\section{Introduction}

Natural resource professions are facing two major problems: a paucity of young adults entering the natural resource field and a lack of diversity in the natural resource field. Pending retirement of many natural resource professionals may result in a loss of institutional memory and core competencies (Minority Outreach Subcommittee 1998; Outley 2008), which can have incalculable consequences for natural resource organizations. In addition, filling vacancies left 
by retiring professionals may prove difficult because of a stagnant and declining enrollment in degree programs over the past three decades (Sharik 2012). Consequences of reduction in expertise on the ability of natural resource organizations to solve environmental problems will only be compounded by the lack of cultural diversity in the field. Lack of a diverse student body and future workforce will further decrease the ability of natural resource organizations to create innovative solutions for complex environmental problems (Organization for Tropical Studies 2007).

Although currently on the rise, enrollment in natural resource degree programs has not increased overall in the past three decades (Sharik 2012), which has resulted in a small and possibly shrinking pool of applicants for natural resource positions. Natural resource majors are some of the least popular majors among bachelor degree holders with less than one half of one percent of graduates holding a natural resource degree (Carnevale et al. 2011; Sharik, 2012). When combined with agriculture degrees (as natural resource degrees often are), the total number of graduates only increases to 1.6 percent of all bachelor degree holders (Carnevale et al. 2011).

One reason for low enrollment numbers in natural resource programs may be the skewed demographics typically found in these programs. Gender makeup of agriculture/natural resource degree holders is 70 percent male and 30 percent female: the second lowest percentage of female degree holders when compared to all other major groups (Carnevale et al. 2011). Racial composition of agriculture/natural resource degree holders is even more skewed. Ninety percent of agriculture/natural resource degree holders are White; four percent are Hispanic; three percent are Asian; and two percent are African-American (Carnevale et al. 2011). When compared to all 
other major groups, the racial composition of agriculture/natural resource majors is more heavily skewed toward White degree holders than any other major (Carnevale et al. 2011).

While natural resource programs struggle to attract young adults and underrepresented groups, the United States is becoming an increasingly ethnically diverse country (U.S Department of Commerce Economics and Statistics Administration 2011). The disconnect between the population of the natural resource field and the American public highlights the need to change recruitment and retention practices. To recruit and retain more young adults and underrepresented groups, knowledge must be gained about specific variables that influence the choice of natural resource majors. The purpose of this study is to theoretically examine barriers to and supports of pursuing a degree in natural resources, to help alleviate the discussed problems.

\section{Theoretical Framework}

Few studies have specifically examined supports and barriers influencing natural resource major choices, with even fewer focusing on choices of underrepresented groups. Past studies have highlighted various barriers to choosing a natural resource-related major, including lack of natural resource career information (e.g. Adams and Moreno 1998; Bowman and Shepard 1985; Maughan et al. 2001; Outley 2008), discrimination (e.g. Chesney 1981; Washington and Rodney 1986), lack of role models (Organization for Tropical Studies 2007), lack of support from family and friends (Outley 2008), limited funding opportunities (Organization for Tropical Studies 2007), and general negative perceptions of careers (Chesney 1981; Leatherberry 1988; Outley 2008). Reported supports for pursuing a natural resource-related field were parental support (Washington and Rodney 1986; Wildman and Torres 2001), role models and mentors (Outley 2008), hands-on experience (Bowman and Shepard 1985; Wildman and Torres 2001), financial 
incentives/support (Outley 2008; Wildman and Torres 2001), and availability of jobs (Conroy 2000; Esters 2007). Unfortunately, most of these past studies have lacked theoretical underpinnings needed to expand hypothesis testing and understanding.

The Social Cognitive Career Theory (SCCT) offers a useful framework for examining factors influencing natural resource career choice of diverse individuals (Lent et al. 2000). The SCCT is suitable for this study because it examines the individual's career development within his or her cultural and environmental context, while also considering personal agency in the choice process. The SCCT incorporates three central social cognitive variables (self-efficacy, outcome expectations, and personal goals) from the social cognitive theory (Bandura 1986) and includes interests as an additional building block of career development (Lent et al. 1994; Lent et al. 2002). More importantly for this study, the SCCT recognizes that social cognitive variables are not solely responsible for shaping career outcomes by highlighting important person (e.g. ethnicity, gender) and contextual variables (supports, barriers) (Lent et al. 1994; Lent et al. 2002).

Core social cognitive and contextual variables represent the set of influences that are particularly important during active phases of career decision making (Lent and Brown 2006, Figure 1). Supports and barriers along the career path can help to shape learning processes/experiences that determine interests in and choice of natural resource careers (Lent et al. 1994; Lent and Brown 2006). In addition, supports and barriers are building blocks of real and perceived opportunity structure within which career plans are devised and implemented (Lent et al. 1994). Notably, perception of supports and barriers throughout the career path is highly influenced by person factors (e.g. gender, ethnicity), which is of particular interest in this study (Lent et al. 1994; Lent et al. 2000). Specifically, this study seeks to examine two main 
research questions through the lens of the SCCT: (1) What supports and barriers influenced a undergraduate's decision to pursue a natural resource major?, and (2) How do sociodemographic factors influence perceived supports and barriers?

\section{Methodology}

This study employed basic interpretive qualitative research design (Patton 2002). Qualitative research design was best suited to provide insight into natural resource major choice because it: 1) seeks to understand experiences and meanings people make of experiences, 2) studies a person in the context of their interpersonal environment, and 3) explores a little researched phenomenon for which standardized instruments have not been developed (Patton 2002).

\section{Sample Selection}

The goal for sample selection was to specifically identify participants who would contribute valuable insight about natural resource degrees. Therefore, we purposefully sampled undergraduates at West Virginia University (WVU) and Alabama A\&M University (AAMU) using criterion sampling. Participants were selected based on the following criteria: 1) undergraduate status, 2) natural resource major and 3) socio-demographic factors (race/ethnicity and gender).

WVU undergraduates were selected and contacted via email by program coordinators from all natural resource programs (Forest Resources Management, Recreation Parks and Tourism, Wildlife and Fisheries, and Wood Science and Technology). Due to a lack of cultural diversity at WVU, all natural resource undergraduates from ethnic minorities were asked to participate. To further increase the cultural diversity of the sample, researchers solicited 
volunteers from AAMU (a historically black university). AAMU faculty recruited undergraduate students in Forestry programs and provided contact information to the researchers. Researchers followed-up with emails and phone calls to all selected WVU and AAMU students. Additional volunteers were contacted until reaching theoretical saturation (when undergraduate interviews revealed no new or relevant themes; Thomson 2011).

\section{Data Collection}

Semi-structured, open-ended interviews (Newman and Benz 1998) were conducted September 2013 - February 2014. Interviews were conducted face-to-face with WVU students and via Skype with AAMU students. Questions derived from previous SCCT research on supports and barriers (e.g. Lent et al. 2002; Diaz 2010; Hosoi 2010; Wicker 2008) were included in an interview guide, ensuring that the same lines of inquiry were pursued with each participant. However, the interviewer was free to probe and ask further questions. Pilot interviews were used to refine the interview guide and style, as well as to determine additional questions. Interviews lasted 15 - 40 minutes and were recorded using a digital-voice or MP3 Skype recorder.

\section{Data Analysis}

Recorded interviews were transcribed verbatim and checked line-by-line. Data were hand-coded and divided into meaningful analytical units using NVivo 10. Content-analysis using a mix of a priori and emergent coding techniques was used to ensure exhaustiveness of analysis (Stemler 2001). A priori criteria was derived from SCCT theoretical background to include themes already cited as important in the literature. After a priori coding was applied, data were reanalyzed to allow additional themes and sub-themes to emerge. Coding units were defined as recording units or ideas belonging to only one category (Stemler 2001). To ensure credibility and accuracy of the research findings, preliminary findings were reported back to select participants 
for review. In addition, all members of the research team reviewed and agreed upon coding schemes.

\section{Results}

\section{Demographics}

Twenty-two culturally diverse, undergraduate, natural resource majors were interviewed (Table 1). Undergraduates ranged from $19-30$ years of age and enrolled in a natural resource program from 2009 - 2013. Twelve of the students were enrolled in other degree programs before switching to natural resources including communications, biology, general studies, accounting, philosophy, and construction management.

\section{Barriers and Supports to Undergraduates}

Undergraduates encountered a wide range of barriers to pursuing a natural resource degree. All barriers discussed fit into four main thematic categories: institutional (school or work-related barriers), financial, familial and social, and discrimination (Table 2). Undergraduates also discussed a wide range of supports that fit into four main thematic categories: instrumental assistance (without which they would not succeed), financial, familial and social, and role models/mentors (Table 3).

\section{Lack of Knowledge}

Institutional barriers were the most commonly mentioned barriers by undergraduates, with lack of knowledge about the natural resource field being most common (16 undergraduates). Lack of knowledge or awareness about the field resulted in 15 of the undergraduates not even considering natural resources until after entering their university. One white male described this lack of knowledge: 
The only issue I had is...they don't really make it very well-known for high school kids. Most people want to go to be doctors, or lawyers, and business degrees, and engineering...you don't really hear a whole lot about natural resources... The people that I tried talking to didn't know or couldn't help me out.

Lack of knowledge of the field also continued while pursuing a natural resource major. Undergraduates discussed being unsure how to get the experience they need to be a successful natural resource professional (4 undergraduates). For example, a black female said:

I didn't know anything about these programs, like USA jobs. I didn't know anything about summer internships for my major. [At my university] there's not much buzz about trying to get a summer internship. So I just feel like I had a lack of knowledge about it...

Undergraduates also expressed course work as a barrier (8 undergraduates), which was

often related to not knowing what to expect from the major. A white male discussed this barrier:

The only thing we had was a math placement test and I didn't do so good. I was in math workshop for a whole year and in forestry you have to pass math as your first class to get through anything...it set me back an entire year. If I had known that forestry is all math, it would've probably have steered me in a different direction because math isn't my biggest forte.

Lack of knowledge about the field also created a familial or social barrier for undergraduates. The most mentioned social barriers stemmed from a lack of family knowledge (6 undergraduates), which may often led to parents wanting undergraduates to select a different major (6 undergraduates). All six of the undergraduates that discussed lack of family knowledge of the field were from underrepresented groups (females or ethnic minorities). A black female discussed these barriers:

So when I first talked to my family about doing something with natural resources, everybody was against it. And I stopped talking to a few of my family members because they thought that I was doing nothing with my life... because they didn't see anything in forestry.... because they thought I wasn't going to make any money, and they didn't know anything about forestry. And they wanted me to be a doctor. 
In addition to family, undergraduates also discussed friends having a lack of knowledge

of the field, which they viewed as a social barrier (4 undergraduates). A white female discussed this barrier:

When I talk to people... who aren't in natural resources fields, they there like "wait...what are you doing?" And they don't understand it. I'll explain it to them and they'll say, "that makes sense. I thought you were doing something weird." They don't really understand what it is or what is really going on...they don't understand unless they're in the field...

\section{Non-Traditional Backgrounds}

Many barriers were uniquely perceived by students from non-traditional backgrounds (traditionally natural resource professionals are rural-raised, land grant University fisheries/wildlife/forestry-educated, anglers/hunters; Minority Outreach Subcommittee 1998), regardless of ethnicity. Nine students described institutional barriers faced because of their nontraditional background, which included difficulty in courses, inability to get scholarships, and being uncomfortable participating in hands-on activities. A black female discussed institutional barriers faced because of a non-traditional background in the following way:

A lot of my introductory courses, they kind of already assumed that I had been outside my whole life...They basically started above where my knowledge was. So I basically had to play catch-up to get to where they were. So that's the only barrier. I'm really smart. I'm book smart. My education is good. But in terms of doing so much other work to get to where everybody else was...it was kind of an issue...

A white female describes how being from a non-traditional background has prevented her from getting scholarships:

For a lot of those scholarships you have to be in the Forestry Society for years. A lot of people know about those things and are getting involved in high school...And for some of us that are from the city, we don't know what that is... and I am not going to join the club, if I don't know the beginning of what it is. Are you going to teach me or I am going to feel really uncomfortable because I don't know anything? I'm not going to learn about these things unless there is someone to teach me that. And then I'm not applicable for those scholarships because I don't know that stuff. 
Being from a non-traditional background also caused some students ( 5 undergraduates) to experience social barriers and a feeling of "not fitting in." A white male described "not fitting in":

It was kind of interesting, you know, I'm not from the country by any means... So initially coming into the program there was definitely a group of country boys... and I had trouble just finding a group to fit into...

At times, social and institutional barriers were also perceived as discrimination-type barriers. Some students from non-traditional backgrounds felt that they were treated differently by faculty or in the field ( 5 undergraduates). For example, a white male discusses being treated differently because of a non-traditional background:

I feel like there's a stereotype of big burly men with beards and I definitely do not fit in that category whatsoever. And that's one of the reasons, believe it or not, that they pushed me towards arboriculture... because I just didn't fit in...

\section{Gender Discrimination}

Gender discrimination was the only discrimination barrier discussed specifically by an underrepresented group (5 female undergraduates). Gender discrimination was experienced by female undergraduates in a number of settings, such as at the university or when applying for internships. For example, a white female discussed experiencing discrimination with in her degree program:

When you're in the major, if you are a girl and you start out, you don't have any respect... Maybe not all advisors, but professors and advisors just kind of have this "oh you're a girl. You came because you wanted to play with animals, or you wanted to save the world, or something... and you have no idea how hard it's going to be, or how much physical demand, or how dirty you are going to be getting out in the field" mentality...And so I feel like they just have this kind of "oh well, you'll probably aren't going to last" idea...At the beginning like I didn't feel like anyone gave me a lot of support. I just didn't feel supported. 
Another white female discussed experiencing gender discrimination when applying for internships in the field:

When I interviewed at [commercial forestry company], the guy expressed doubt that I could actually do the physical labor. So that was why I ended up getting an internship at a nature center because I didn't want to work for someone like that. It might narrow my career choices...I like to think that it was just one or two people and not forestry as a whole...

All of the women discussed needing persistence to overcome discrimination barriers. A

biracial female even discussed using the discrimination to fuel her success:

I have heard, "you can't do it because you're a girl.” But for me that just kind of makes me want to go, "okay watch me." I'm a little rebellious I guess you could say. And I hate being told that I can't do something. It just makes me to work for it that much harder.

\section{Professors as Instrumental Support and Role Models}

All undergraduates talked generally about the support they received from their professors, such as "I've got two or three teachers that I talk to on a daily basis that help me with everything I need. I can just go talk to them about anything." However, many undergraduates viewed support from their professors as integral to their success in a natural resource major (20 undergraduates). For example, a white female discussed how professors prevented her from changing majors:

If I've ever had any questions about forestry, they've always answered them. For a while I was thinking about switching my major, so [my professors] talked me out of it. I was thinking about switching just because I had that whole bad experience getting an internship...I thought maybe it would be easier as a girl, but I decided stay here because I really like the major and the program...

Undergraduates also used their professors as integral emotional and psychological

support. A biracial female saw her professor as an instrumental source of emotional support:

When I'm at school, [my professor] is like a second father to me because he's from the same area I am. And, you know, he's seen a lot of what I've seen...Because I am for the most part very much family-oriented, it means a lot to have a connection to home. So I'm not so homesick. So I'm not so lonely. 
In addition to being an instrumental support, undergraduates viewed their professors as

role models and mentors (12 undergraduates). A black male discussed his professor as a mentor:

[My professor] is an individual that has goes gone above and beyond the call. He plays a vital role as an educator, as well as someone that you can go to for life issues help...a lot of things that I've gained at [my university], it was through him...

In addition, a black male discussed his professor as a role model for his future career:

One professor that I really look to...just works hard in natural resources and forestry. And he has lots of knowledge, and experience, and wisdom that have driven him to have a successful career.

\section{Early Work Experience}

Undergraduates viewed early work experience as an instrumental support to pursuing a natural resource degree (11 undergraduates). Early work experience was seen as a way of preparing for a future career for most undergraduates. However, for three undergraduates, their early work experience was a pivotal part of them choosing a natural resource program. A white male discussed how a high school internship inspired him to study natural resources:

I worked at a state park and a wildlife rehab center...And everybody that I had worked with had gone to college for natural resource majors, so that's how I kind of learned more about it...it helped me decide what opportunities I had, and what I could do with myself for the future, and kind of gave me the right path to go on towards my future.

A black male pursuing a non-natural resource major decided to switch majors after struggling to find a field that satisfied him, "Everything other than Forestry, I found to be unsatisfying. It was really just the type of work that I could do and the process of elimination really..." Having a positive internship experience while pursuing other degrees finally led him to a natural resource degree, "I'd done an internship with the Student Conservation Association and changed my major to Forestry after I did that." 


\section{Student Community}

Undergraduates used the community within their natural resource program as a source of social support, as well as a tool to help them overcome barriers that they faced. Undergraduates discussed tight-knit program community (10 undergraduates), friends enjoying outdoor activities (14 undergraduates), and being involved in student natural resource organizations (20 undergraduates) as sources of social support. A white male describes how the tight-knit community is an advantage:

Definitely having some friends really helps here. There is really no excuse [to not be connected], I feel like, for people that are already in the major because everybody knows your name. That's why I like the major really because it's very close-knit group...not like if you are an accounting major with 5,000 other kids.

Part of what makes the community so tight-knit is heavy involvement in one or more student natural resource organizations. Natural resource organizations provide a social connection to fellow undergraduates, graduate students, and professors. For example, a white male discusses creating a meaningful social connection with a graduate student through participating in a student organization:

When I joined the Wildlife Society, he was a grad student that was helping out with that. So I met him through that. And then he had this experience where you could work on bear habitat surveys and I volunteered for that. And I just got to know him more and more...

A biracial female described how student organizations are essential to her success:

Being able to spend time with them makes a difference too...I get bored easily and without something to help focus me like the forestry club, or SAF, or the wildlife club... without all of that, I don't know what I would do... 


\section{Discussion and Recommendations}

Similar to a study by Lent et al. (2002) examining barriers in math and sciences, this study found four main thematic categories of barriers: financial, institutional, social and familial, and discrimination (Betz 2008). Overall, a lack of knowledge of the natural resource field was the most mentioned barrier, which is consistent with past research findings on natural resourcerelated careers (Adams and Moreno 1998; Bowman and Shepard 1985; Maughan et al. 2001; Outley 2008). As a result of lack of knowledge, the majority (15 of 22) of undergraduates did not consider a natural resource major until after entering their university. Therefore, natural resource programs may want to focus efforts on early and extensive advertisement of major options in high school. Using a hands-on approach and hosting natural resource program fairs, which introduce high school students to the program may be an effective way to recruit (recommended by 6 undergraduates). In addition, natural resource program advertisement should continue at the undergraduate level to compensate for lack of awareness at the high school level. Twelve of the twenty-two undergraduates pursued another major before natural resources.

Lack of knowledge may also impact the level of familial support for pursuing a natural resource degree. Therefore, natural resource programs potentially need to educate not only young adults, but also families about major options and career pathways. Interestingly, lack of familial support was more commonly perceived by undergraduates from underrepresented groups. Ethnic groups with traditional collectivist values (e.g. Mexican Americans), individuals in more isolated communities (e.g. rural Appalachia), and women often emphasize the support of family in academic and career decision making (Ali \& Saunders 2006; Flores and O'Brien 2002; Tang et al. 1999; Wetterson et al. 2005). Thus, when trying to recruit underrepresented groups, natural resource programs may want to communicate consistently and thoroughly with families. 
Undergraduates from non-traditional backgrounds (city-raised, non-anglers/hunters) perceived more barriers to pursuing a natural resource career than students from traditional backgrounds. In the case of natural resource programs, non-traditional students may be considered an underrepresented group and may face similar barriers. In past SCCT research on non-traditional careers, underrepresented groups generally perceived more barriers (Luzzo and McWhiter 2001). Consequently, natural resource programs may need to use specialized recruitment and retention techniques for non-traditional students. For example, a summer short course could be offered to students with less experience in natural resources to prepare them for the major. Additionally, early work or volunteer experiences tailored to increase comfort level of non-traditional students with technical skills could help alleviate social and coursework barriers.

Although discrimination did not prevent interviewed undergraduates from pursuing a natural resource degree, female undergraduates perceived gender discrimination in the natural resource field. Unfortunately, due to time and funding constraints this study was not able to interview young adults that did not enter the natural resource field, but past studies have found that discrimination has prevented young adults from entering natural resource careers (e.g. Chesney 1981; Washington and Rodney 1986). For natural resource degree programs, discrimination may be a factor that impacts student retention in addition to recruitment. Therefore, extra support systems for female students may be essential. Connecting students to organizations for underrepresented groups, such as Minorities in Agriculture and Natural Resource Related Sciences (MANRRS), may help students overcome discrimination barriers.

Supports to career pursuit also fit into four main thematic categories: social support and encouragement, instrumental assistance, role models and mentors, and financial resources (Lent et al. 2002; Betz 2008). Undergraduates emphasized the importance of professors (both as 
instrumental assistance and role models/mentors). Role models have been considered to be a support to natural resource-related career pursuit in the past (Outley 2008). In addition, role models have been shown to be more influential on women, ethnic minorities, and students with lower socio-economic status (Gushue and Whitson 2006; Kenny et al. 2007). Given the importance of professors as role models, professors in natural resource programs may benefit from mentorship training opportunities. Professors could also be connected with a student early in their undergraduate career or high school to provide them with course and career guidance.

Undergraduates discussed the importance of early work experience and paid internships, both of which were found to be important in past studies (Bowman and Shepard 1985; Wildman and Torres 2001). Natural resource programs may be able to increase recruitment by creating innovative ways to provide early field experience to young adults, while continuing to offer paid internships and volunteer opportunities. Strategies could include working with public land agencies to create field-based, service learning courses to introduce a variety of majors to natural resources. Focusing early experience efforts on other disciplines and diverse skill sets may help to attract more culturally diverse students.

Undergraduates discussed the importance of the close-knit natural resource program community. The close-knit aspect of the programs may be a key point to express during the recruitment process, especially when targeting underrepresented groups. Social supports have also been shown to neutralize impacts of barriers along the academic or career path of women and ethnic minorities (Lent et al. 2011; Quimby and O’Brien 2004). Helping students identify social supports early-on in their degree decision-making process may help them choose and continue in a natural resource major. 


\section{Conclusion}

Undergraduate interviews emphasized specific barriers to young adults and underrepresented groups pursuing natural resources. The difference between barriers and supports perceived by undergraduates emphasizes the need to design recruitment and retention techniques for specific target populations. By carefully designing support systems for young adults and underrepresented groups, natural resource degree programs can help them overcome barriers and enter the natural resource workforce. Future research should include undergraduates that started as a natural resource major, but were unable to persist because of barriers. Undergraduates that did not persist in natural resource majors would reveal barriers large enough to deter an individual from pursuing a natural resource career. 


\section{Tables}

Table 1. Demographic data from 22 undergraduates.

Table 2. Barriers faced by undergraduates followed by the number of students that discussed the barrier.

Table 3. Supports felt by undergraduates followed by the number of students that discussed the support.

\section{Figures}

Figure 1. Social Cognitive Career Theory Model

The SCCT model of person, contextual, and experiential factors affecting career-related choice behavior. Variables in shaded boxes represent the core/proximal social cognitive and contextual variables. Note that the directional arrows in the framework illustrate what are believed to be the predominant causal pathways; however, based on the triadic casual view, the elements influence one another bi-directionally (Lent et al, 1994). Source. Lent and Brown (2006) 


\section{References}

Adams, C.E., and M. Moreno. 1998. A comparative study of natural resource professionals in minority and majority groups in the Southeastern United States. Wildlife Soc B.(4): 971-981.

Ali, S. R., and J.L. Saunders. 2006. College expectations of rural Appalachian youth: An exploration of social cognitive career theory factors. Career Dev Q. 55: 38-52.

Bandura, A. (1986). Social foundations of thought and action: A social cognitive theory. Prentice-Hall, Englewood Cliffs, NJ. 617p.

Betz, N.E. 2008. Advances in vocational theories. P. 357-374 in Handbook Of Counseling Psychology. S. Brown and R. Lent (eds.). Wiley, New York, NY.

Bowman, M.L., and C.L. Shepard. 1985. Introducing minorities to natural resource career opportunities. Ohio J Sci. 85, 29-33.

Carnevale, A.P., J. Strohl, and M. Melton. 2011. What is it worth? The economic values of college majors. Available online at http://cew.georgetown.edu/whatsitworth; last accessed Sept. 9, 2013.

Chesney, C.E. 1981. Should racial minorities consider careers in natural resources? J Non-white Con. 41(4): 146-153.

Conroy, C.A. 2000. Reinventing career education and recruitment in agricultural education for the $21^{\text {st }}$ century. J Agr Educ. 41: 73-84.

Diaz, W. 2010. Relationship of perceived barriers to career self-efficacy among Latino undergraduates at a New England regional public university. Ph.D. dissertation, Johnson \& Wales Univ., Providence, Rhode Island. 164p.

Esters, L.T. 2007. Factors influencing postsecondary education enrollment behaviors of urban agricultural education students. Career Tech Ed Res. 32: 79-98.

Flores, L. Y., and K.M O’Brien. 2002. The career development of Mexican American adolescent women: A test of social cognitive career theory. J Couns Psychol. 49: 14-27.

Gushue, G. V., and M.L. Whitson. 2006. The relationship among support, ethnic identity, career decision self-efficacy, and outcome expectations in Africa American high school students. $J$ Career Dev. 33: 112-124.

Hosoi, S.A. 2010. Culture matters: Factors affecting the persistence of European American and Asian women in two U.S. engineering doctoral programs. Ph.D. Dissertation, Colorado State Univ., Fort Collins, CO. 146p. 
Kenny, M. E., L. Gualdron, D. Scanlon, E. Sparks, D.L. Blustein, and M. Jernigan. 2007. Urban adolescents' constructions of supports and barriers to educational and career attainment. J Couns Psychol. 54: 336-343.

Leatherberry, E.C. 1988. Black high school students' images of forestry as a profession. J Negro Educ, 57: 208-219.

Lent, R.W. 2005. A social cognitive view of career development and counseling. P. 101-237 in Career development and counseling: Putting theory and research to work. S.D. Brown and R.W. Lent (eds.). Wiley, New York, NY.

Lent, R.W., and S.D. Brown. 2006. On conceptualizing and assessing social cognitive constructs in career research: A measurement guide. J Career Assessment. 14: 12-35.

Lent, R.W., S.D. Brown, and G. Hackett. 1994. Toward a unifying social cognitive theory of career and academic interest, choice, and performance. J Vocat Behav. 45:79-122.

Lent, R. W., S.D. Brown, and G. Hackett. 2000. Contextual supports and barriers to career choice: A social cognitive analysis. J Counsel Psychol. 47: 36-49.

Lent, R.W., S.D. Brown, R. Talleyrand, E.B. McPartland, T. Davis, S.B. Chopra, M.S. Alexander, V. Sutherakaran, and M. Chai. 2002. Career choice barriers, supports, and coping strategies: College students' experiences. J Vocat Behav. 60: 61-72.

Lent, R.W., S.D. Brown, H. Sheu, J. Schmidt, B.R. Brenner, C.S. Gloster, and et al. (2005). Social cognitive predictors of academic interests and goals in engineering: Utility for women and students at historically Black universities. J Counsel Psychol. 52: 84-92.

Lent, R.W., F.G. Lopez, H. Sheu, and A.M. Lopez. 2011. Social cognitive predictors of the interests and choices of computing majors: Applicability to underrepresented students. $J$ Vocat Behav. 78: 184-192.

Luzzo, D. A., and E.H. McWhirter. 2001. Sex and ethnic differences in the perception of educational and career-related barriers and levels of coping efficacy. J Couns Dev. 79: 61-67.

Maughan, O.E., D.L. Bounds, S.M. Morales, and S.V. Villega. 2001. A successful educational program for minority students in natural resources. Wildlife Soc Bul. 29: 917-928.

Minority Outreach Subcommittee. 1998. Executive summary on a nationwide assessment of the status of State Fish and Wildlife Agencies' efforts to research minorities in their education and outreach programs. U.S. Fish and Wildlife. Available online at http://www.funoutdoors.com/files/Minority\%20Outreach\%20Subcommittee\%20Report.pdf; last accessed Sept. 9, 2013. 
Newman, I., and C.R. Benz. 1998. Qualitative-quantitative research methodology. Exploring the interactive continuum. Southern Illinois University Press, Carbondale and Edwardsville, IL. 240p.

Organization for Tropical Studies. (2007). Advisory Committee for Academic Diversity manual of best practices for recruiting and retaining underrepresented groups in ecology and the environmental sciences. Found online at http://www.obfs.org/assets/docs/humandiversity/manual-bestpractice.pdf; last accessed Sept. 92013.

Outley, C.W. 2008. Perceptions of agriculture and natural resource careers among minority students in a national organization. USDA For. Serv. Gen. Tech. Rep. PSW-GTR-210. 15p.

Patton, M.Q. 2002. Qualitative research and evaluation methods ( $3^{\text {rd }}$ ed.). Sage Publication Ltd.. Thousand Oaks, CA. 598p.

Quimby, J. L., and K.M. O’Brien. 2004. Predictors of student and career decisionmaking self-efficacy among nontraditional college women. Career Dev Q. 52: 323-339.

Sharik, T.L., R.J. Liliehold, and Richardson. Factors influencing undergraduate enrollment trends in natural resources. Paper, $9^{\text {th }}$ Biennial Conference on University Education in Natural Resources, Fort Collins, CO., March 22, 2012.

Stemler, S. 2001. An overview of content analysis. Practical Assessment, Research, and Evaluation, 7. Available online at http://PAREonline.net/getvn.asp? $\mathrm{v}=7 \& \mathrm{n}=17$; last accessed Sept. 9, 2013.

Tang, M., N.A. Fouad, and P.L. Smith. 1999. Asian American's career choices: A path model to examine factors influencing their career choices. J Vocat Behav. 54: 142-157.

Thomson, S.B. 2011. Sample size and grounded theory. J Admin and Govern. 5: 45-52. Washington, W.J. and H.E. Rodney. 1986. How do students learn about natural-resource careers? J Forest. 81: 22-24.

U.S Department of Commerce Economics and Statistics Administration. 2011. Overview of race and Hispanic origin: 2010. 2010 Census Briefs. U.S. Census Bureau Tech. Rep. 24p.

Wettersten, K. B., A. Guilmino, C.G. Herrick, P.J. Hunter, G.Y. Kim, T. Beecher, and et al. 2005. Predicting educational and vocational attitudes among rural high school students. J Counsel Psychol. 52: 658-663.

Wicker, I. 2008. African American women athletics administrators: pathway to leadership positions in the NCAA a qualitative analysis. Ph.D. Dissertation, North Carolina State University, Raleigh, NC. 150p.

Wildman, M., and R.M. Torres. 2001. Factors identified when selecting a major in agriculture. $J$ Agr Educ. 42 (2): 46-55. 
Figure 1. Social Cognitive Career Theory Model

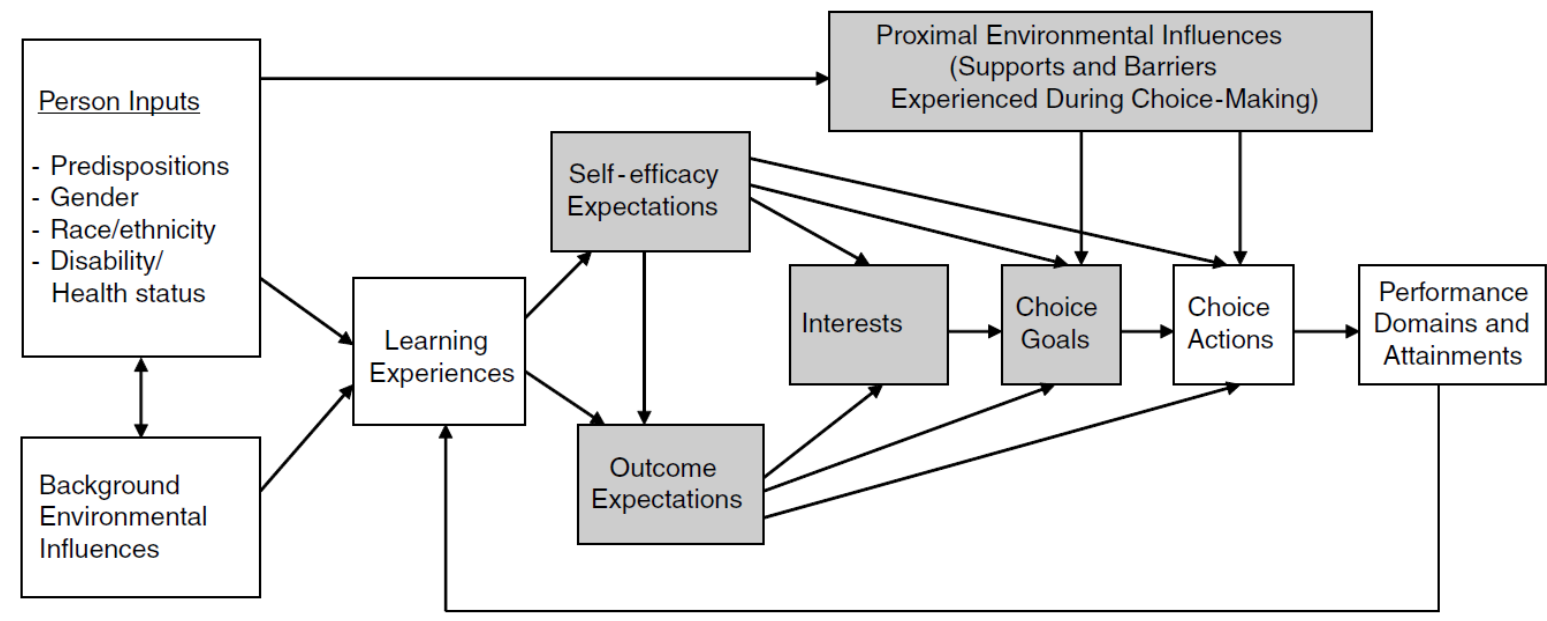


Table 1. Demographic data of 22 undergraduate natural resource majors

\begin{tabular}{|c|c|c|}
\hline & & $\begin{array}{c}\text { \# of } \\
\text { Students }\end{array}$ \\
\hline \multirow[t]{2}{*}{ Gender } & Female & 9 \\
\hline & Male & 13 \\
\hline \multirow[t]{6}{*}{ Race/Ethnicity } & White & 14 \\
\hline & Black & 4 \\
\hline & Lebanese/White & 1 \\
\hline & Asian & 1 \\
\hline & Black/White & 1 \\
\hline & $\begin{array}{l}\text { Native American/ } \\
\text { White }\end{array}$ & 1 \\
\hline \multirow[t]{4}{*}{ Class Level } & Freshman & 1 \\
\hline & Sophomore & 3 \\
\hline & Junior & 10 \\
\hline & Senior & 8 \\
\hline
\end{tabular}


Table 2. Barriers faced by undergraduates followed by the number of students that discussed the barrier.

\begin{tabular}{|c|c|c|c|}
\hline & \# & & \# \\
\hline Financial & & Familial and Social & \\
\hline Lack of Scholarships in Field & 7 & Lack of Family Understanding of the Field & 6 \\
\hline College Tuition & 6 & Parents Wanted a Different Major & 6 \\
\hline Earning Potential in Field & 3 & Lack of Friend Understanding of the Field & 5 \\
\hline Need to Contribute to Family & 1 & Did Not Fit in with Classmates & 5 \\
\hline \multirow[t]{2}{*}{ Single Parent Income } & 1 & Intimidated Due to Lack of Experience & 3 \\
\hline & & College-Related Social Distractions & 2 \\
\hline Institutional & & Discrimination & \\
\hline Lack of Knowledge of the Field & 16 & Discrimination Based on Gender & 5 \\
\hline Non-Tradition Background & 9 & Faculty Insensitive to Non-Tradition Background & 5 \\
\hline Natural Resource Course Work & 8 & Reverse Discrimination & 1 \\
\hline Unsure How to Get Experience & 4 & & \\
\hline First Generation College Student & 2 & & \\
\hline Lack of Job Openings in the Field & 2 & & \\
\hline Older Faculty & 1 & & \\
\hline
\end{tabular}


Table 3. Supports felt by undergraduates followed by the number of students that discussed the support.

\begin{tabular}{|c|c|c|c|}
\hline & \# & & \# \\
\hline \multicolumn{2}{|l|}{ Financial } & \multicolumn{2}{|l|}{$\underline{\text { Role Models and Mentors }}$} \\
\hline Scholarships & 12 & Professors & 12 \\
\hline Parental Monetary Support & 12 & Parents/Grandparents & 9 \\
\hline Reciprocal (In-State) Tuition & 5 & Upper Classman and University Graduates & 7 \\
\hline Grants & 4 & Local Professional & 5 \\
\hline On-Campus Job & 4 & Formal Mentor Program & 2 \\
\hline & & Sibling & 1 \\
\hline Instrumental Assistance & & Social & \\
\hline Professors & 20 & University Natural Resource Clubs/Groups & 20 \\
\hline Early Work Experience & 11 & General Family Support & 18 \\
\hline Local Professional & 6 & Friends Enjoy Outdoor Activities & 14 \\
\hline High School Guidance Counselor & 4 & Close Knit Program Community & 8 \\
\hline Working with Graduate Students & 4 & Boy Scouts & 3 \\
\hline College Course Work & 4 & Community Support & 3 \\
\hline High School Course/Teacher & 3 & Volunteering in the Community & 2 \\
\hline Recruiters/Career Fairs & 3 & & \\
\hline First Generation Support Group & 1 & & \\
\hline Professional Mentor & 1 & & \\
\hline
\end{tabular}


Chapter 4: Article 3

Barriers to Pursuing a Natural Resource Degree and Career

Kelly Balcarczyk

Dave Smaldone

Steve Selin

(This article was prepared for the Journal of Environmental Education)

\begin{abstract}
Many natural resource professionals are reaching retirement and attracting young adults to fill vacancies may prove difficult. This study aims to contribute to research on natural resource career choice by examining barriers encountered throughout career development. Semistructured interviews based on the Social Cognitive Career Theory were used to assess the barriers that influenced the careers of 22 undergraduates and 22 recent hires. All barriers fit into 4 main thematic categories: financial, institutional, social/familial, and discrimination. Differences between barriers perceived by particular groups highlighted the need to design recruitment and retention techniques for specific target populations.
\end{abstract}

Key Words: barriers, career choice, recruitment, retention

\title{
Introduction
}

Government agencies, particularly those charged with managing the nation's natural resources, are facing a human resource crisis because of the pending retirement of many professionals. The Federal workforce is older than Federal workforces of past decades. Not surprisingly, natural resource agencies mirror government-wide statistics with over 40 percent of the workforce over 50 years of age (Copeland, 2011). With many career natural resource professionals reaching retirement age, agencies may see a loss of institutional memory and core competencies, such as leadership and science expertise (Outley, 2008). However, this high rate 
of retirement also presents an opportunity to hire talented young adults interested in natural resource careers.

Unfortunately, attracting young adults to fill the vacancies left by retiring natural resource employees may prove difficult. Although currently on the rise from a recent fall, enrollment in natural resource degree programs has not increased in the past three decades (Sharik, 2012), which has resulted in a small and possibly shrinking pool of applicants for natural resource positions. In fact, natural resource majors are some of the least popular majors with less than one half of one percent of all college graduates holding a natural resource degree (Carnevale, Strohl, \& Melton, 2011).

One reason for the low enrollment numbers in natural resource programs may be the skewed demographics typically found in these programs. The gender makeup of natural resource degree holders is 70 percent male and 30 percent female: the second lowest percentage of female degree holders when compared to all other major groups (Carnevale et al., 2011). The racial composition of natural resource degree holders is even more skewed. Ninety percent of natural resource degree holders are White; four percent are Hispanic; three percent are Asian; and two percent are African-American (Carnevale et al., 2011). When compared to all other major groups, the racial composition of natural resource majors is more heavily skewed toward White degree holders than any other major (Carnevale et al., 2011).

In addition, a study on diversity in environmental/natural resource institutions (Taylor, 2008) found that approximately one-fourth of 29 government agencies and more than one-third of 129 mainstream organizations had not hired any minorities in the three years preceding the study. Moreover, thirty-five percent of widely recognized environmental/natural resource organizations and nineteen percent of government agencies indicated that they had no minorities 
on staff (Taylor, 2008). This lack of cultural diversity in the field can only serve to compound the consequences of mass retirement. Studies have shown that culturally diverse workforces serve to increase the number of innovative solutions for environmental problems (Organization for Tropical Studies, 2007).

While natural resource programs and organizations struggle to attract young adults and underrepresented groups, the U.S. is becoming an increasingly ethnically diverse country (U.S Department of Commerce Economics and Statistics Administration, 2011). The disconnect between the population of the field and the American public highlights the need to assess and potentially change recruitment and retention practices in natural resource degree programs. The purpose of this study is to gain information on barriers and supports that influence the choice of natural resource majors and careers in order to recruit and retain more young adults and underrepresented groups.

Specifically, this study seeks to examine three main research questions through the lens of the Social Cognitive Career Theory: (1) what barriers do recent hires and undergraduates face while pursuing a natural resource career or degree?, (2) how do socio-demographic factors influence the barriers perceived by an undergraduates/recent hires while pursuing a natural resource major or career?, and (3) how do perceived barriers compare between natural resource majors and recent hires?

\section{Theoretical Framework}

Few studies have specifically examined barriers influencing natural resource major and career choices, with even fewer focusing on choices of underrepresented groups. Past studies have highlighted various barriers to choosing a natural resource-related major, including lack of natural resource career information (e.g. Adams \& Moreno, 1998; Bowman \& Shepard, 1985; 
Maughan, Bounds, Morales, \& Villega, 2001), discrimination (e.g. Chesney, 1981; Washington and Rodney, 1986), lack of role models (Organization for Tropical Studies, 2007), lack of support from family and friends (Outley, 2008), limited funding opportunities (Organization for Tropical Studies, 2007), and general negative perceptions of careers (Chesney, 1981; Outley, 2008). Unfortunately, most of these past studies have lacked theoretical underpinnings needed to expand hypothesis testing and understanding.

The Social Cognitive Career Theory (SCCT) offers a useful framework for examining factors influencing natural resource career choice of diverse individuals (Lent, Brown, \& Hackett, 2000). The SCCT is suitable for this study because it examines the individual's career development within their cultural and environmental context, while also considering personal agency in the process. The SCCT incorporates three central variables (self-efficacy, outcome expectations, and personal goals) from the social cognitive theory (Bandura, 1986) and includes interests as an additional building block of career development (Lent, Brown, \& Hackett, 1994; Lent et al., 2002). More importantly for this study, the SCCT recognizes that social cognitive variables are not solely responsible for shaping career outcomes by highlighting important person (e.g. ethnicity, gender) and contextual variables (supports, barriers) (Lent et al., 1994; Lent et al., 2002).

The core social cognitive and contextual variables represent the set of influences that are particularly important during the active phases of career decision making (Lent \& Brown, 2006, Figure 1). Barriers along the career path can help to shape learning processes/experiences that determine interests in and choice of natural resource careers (Lent et al., 1994; Lent \& Brown, 2006). In addition, barriers are building blocks of real and perceived opportunity structure within which career plans are devised and implemented (Lent et al., 1994). Notably, the perception of 
barriers throughout the career path is highly influenced by person factors (e.g. gender, ethnicity), which is of particular interest in this study (Lent et al., 1994; Lent et al., 2000). Within SCCT research, supports and barriers (and the ways in which they complement each other) have been identified as an area of SCCT research needing more emphasis and development, especially concerning underrepresented groups (Lent, 2000). This study hopes to identify unique supports and barriers to natural resource degrees using qualitative methods, which can hopefully inform quantitative likert-type methods typically employed with the SCCT.

\section{Methodology}

This study employed a basic interpretive qualitative research design (Patton, 2002). A qualitative research design was best suited to provide insight into natural resource major and career choice because it: 1) seeks to understand experiences and meanings people make, 2) studies a person in the context of their interpersonal environment, and 3) explores a little researched phenomenon for which standardized instruments have not been developed (Patton, 2002).

\section{Sample Selection}

The goal for sample selection was to specifically identify participants who would contribute valuable insight about natural resource career paths. Therefore, we purposefully sampled two populations: recent hires at the U.S. Fish and Wildlife Service (FWS) and natural resource majors at West Virginia University (WVU) and Alabama A\&M (AAMU). A criterion sampling technique was used to select recent hires based on the following criteria: 1) FWS fulltime, permanent employee, 2) between 18 and 30 years of age, 3) hired by the FWS within the past 3 years, and 4) socio-demographic factors (race and gender). Criterion sampling was also 
used to select undergraduates based on: 1) undergraduate status, 2) natural resource major and 3) socio-demographic factors.

WVU undergraduates were selected and contacted via email by program coordinators of all natural resource programs (Forest Resources Management, Recreation Parks and Tourism Resources, Wildlife and Fisheries, and Wood Science and Technology). Due to a lack of cultural diversity at WVU, all natural resource undergraduates from ethnic minorities were asked to participate. To increase the cultural diversity of the sample, researchers solicited volunteers from AAMU, a historically black university. AAMU faculty recruited undergraduate students in Forestry programs and provided contact information to the researchers. Researchers followed-up with emails and phone calls to all selected WVU and AAMU students. Additional volunteers were contacted and interviewed until reaching theoretical saturation (when undergraduate interviews revealed no new or relevant themes; Thomson, 2011).

Initial FWS recent hire participants were recommended by FWS managers from all regions. Potential participants were initially contacted via email to assess interest in participating. Each initial FWS participant was then asked to recommend three additional recent hires that fit the research criteria. This snowball sampling technique was used until reaching theoretical saturation.

\section{Data Collection}

Semi-structured, open-ended interviews (Newman \& Benz, 1998) were conducted with recent hires (November 2012 - June 2013) and undergraduates (September 2013 - February 2014). Interviews were conducted via Skype with FWS recent hires and AAMU undergraduates. WVU undergraduates were interviewed in-person. Questions derived from previous SCCT research on barriers (e.g. Lent et al., 2002; Diaz, 2010) were included in an interview guide, 
ensuring that the same lines of inquiry were pursued with each participant. However, the interviewer was free to probe and ask further questions. Pilot interviews were used to refine the interview guide and style, as well as to determine additional questions. Interviews lasted $15-80$ minutes and were recorded using a digital-voice or MP3 Skype recorder.

\section{Data Analysis}

Recorded interviews were transcribed verbatim and checked line-by-line. Data was handcoded and divided into meaningful analytical units using NVivo 10. Content-analysis using a mix of a priori and emergent coding techniques was used to ensure exhaustiveness of the analysis (Stemler, 2001). A priori criterion was derived from SCCT theoretical background to include themes already cited as important in the literature. After a priori coding was applied, data was reanalyzed to allow additional themes and sub-themes to emerge. Coding units were defined as recording units or ideas belonging to only one category (Stemler, 2001). To ensure credibility and accuracy of the research findings, preliminary findings were reported back to select participants for review. In addition, all members of the research team reviewed and agreed upon coding schemes.

\section{Results}

\section{Demographics}

Twenty-two culturally diverse natural resource majors were interviewed (Table 1). Undergraduates ranged from 19 - 30 years of age and were enrolled in a natural resource program from 2009 - 2013. In addition, twenty-two FWS recent hires representing eight of nine FWS regions were interviewed (regions 2 - 9; Table 2). 


\section{Barriers}

Recent hires and undergraduates encountered a wide range of barriers to pursuing a natural resource degree and career. All of the barriers discussed by both groups fit into four main thematic categories: financial, institutional (school or work-related barriers), familial and social, and discrimination (Table 3). In general, recent hires in underrepresented groups (females, and ethnic and racial minorities) perceived more barriers throughout their job pursuit than white males. Female undergraduates and students from non-traditional backgrounds (city-raised, nonhunter/anglers) perceived more barriers throughout their degree pursuit, regardless of ethnicity.

\section{$\underline{\text { Financial Barriers }}$}

Both white males and underrepresented groups perceived financial barriers to their degree and career pursuit. While six of the ten financial barriers mentioned could impact young adults pursuing fields other than natural resources, four financial barriers specifically impact young adults in the natural resource field. Financial barriers specific to the natural resource field include, lack of scholarships ( 7 undergraduates), earning potential (3 undergraduates), low pay (5 recent hires from underrepresented groups), and inability to take unpaid internships (3 recent hires from underrepresented groups).

Field-related financial barriers were perceived by both white male and underrepresented undergraduates. However, a white female from a non-traditional natural resource background discussed how her background increased her financial barriers:

For a lot of those scholarships you have to be in the Forestry Society for years. A lot of people know about those things and are getting involved in high school... And for some of us that are like from the city, we don't know what that is.... and I am not going to join in the club, if I don't know the beginning of what it is....and then I'm not applicable for those scholarships because I don't know that stuff. 
Interestingly, field-related financial barriers were specifically discussed by recent hires in underrepresented groups. For example, low pay in the field may be more of a barrier to underrepresented individuals that work in urban offices. A black female discussed pay not matching the cost of living:

For a while, I was still being paid my intern salary while starting my full-time position and it was indeed a financial barrier for quite a while. I was not able to afford an apartment here in the Washington DC metro area and so I rented rooms off of craigslist. And there's whole other safety concern that goes along with that...

$\underline{\text { Institutional Barriers }}$

Institutional barriers were the most commonly mentioned barriers by both recent hires and undergraduates, with lack of knowledge about the field being most common (16 undergraduates; 14 recent hires). As a result of lack of knowledge, the majority (15 of 22) of undergraduates did not consider a natural resource major until after entering their university. In addition, the majority (19 of 22) of recent hires did not consider a career with the FWS until late in their undergraduate or graduate school careers, or after they had begun their careers. A white male undergraduate described his lack of knowledge:

The only issue I had is...they don't really make it very well-known for high school kids. Most people want to go to be doctors or lawyers... you don't really hear a whole lot about natural resources. So that was the only issue that I had. The people that I tried talking to didn't know or couldn't help me out.

A biracial recent hire discussed his lack of knowledge about the field very similarly:

I'd say just it was perhaps just a lack of knowledge as to the career options in this field...from the college that I went to, but also the even in high school. I had no idea that this field existed...I had no idea what natural resources was... I was supposed to be a doctor or a lawyer, not a wildlife biologist. Maybe there was just not any information when I was first thinking about careers. 
Undergraduates from non-traditional backgrounds perceived unique institutional barriers, regardless of ethnicity. Nine students described institutional barriers faced because of their nontraditional background, which included difficulty in courses and being uncomfortable participating in hands-on activities. A black female discussed institutional barriers faced because of her non-traditional background:

A lot of my introductory courses, they kind of already assumed that I had been outside my whole life... They basically started above where my knowledge was. So I basically had to play catch-up to get to where they were...I'm really smart. I'm book smart, but in terms of doing so much other work to get to where everybody else was... it was kind of an issue...

Recent hires from underrepresented groups also perceived unique institutional barriers. Institutional barriers perceived by underrepresented groups were: (1) their university was not aware of FWS programs, (2) FWS structure (barriers related to the way the FWS is organized and managed; i.e. being a top heavy bureau), (3) moving requirements, and (4) lack of skills. A biracial female discussed the moving requirements as a barrier in the natural resource field:

There is a lot of desire to have people move around and basically put career ahead of everything else in our lives. And so I think that that also is a barrier for some people like for me...just trying to decide, am I willing to live X miles away from my family as a sacrifice to have a good career?... there's a lot of stigma placed on people who don't really want to move around a lot within the service...

\section{Familial and Social Barriers}

Underrepresented groups (in both undergraduates and recent hires) perceived more social and familial barriers throughout their degree and career pursuit than white males (Figure 2). However, white males and underrepresented groups both experienced being discouraged from the natural resource field (6 undergraduates, 3 recent hires). For example, a white male recent hire described being discouraged by a high school guidance counselor, "I do remember high 
school counselor telling me that... 'the jobs are too hard to come by,' she said. I'll never get a job."

Both undergraduates and recent hires from underrepresented groups also noted that the lack of family knowledge about the field was a barrier ( 6 undergraduates, 3 recent hires). A black female undergraduate described this lack of family knowledge:

So when I first talked to my family about doing something with natural resources, everybody was against it. And I stopped talking to a few of my family members because they thought that I was doing nothing with my life....because they thought I wasn't going to make any money, and they didn't know anything about forestry.

Similarly, a recent hire biracial male discussed how his family's lack of knowledge was a barrier:

My parents are from the Philippines and they don't have the same kind of values when it comes to the environment and conservation...They don't even have the words in my mother's native language to describe what I do... Almost right after I accepted my job with the service, my mom started sending me applications for other jobs because she didn't think that this was a viable career option.

Undergraduates from non-traditional backgrounds also experienced unique social barriers at the university. Undergraduates described a feeling of "not fitting in" (5 undergraduates). A white male described "not fitting in":

It was kind of interesting, you know, I'm not from the country by any means...So initially coming into the program there was definitely a group of country boys... and I had trouble just finding a group to fit into...

Recent hires from underrepresented groups noted unique social barriers, including cultural dissonance (5 recent hires; all females) and lack of work/life balance (4 recent hires). For example, a black female discussed the barrier of cultural dissonance:

So there were always questions about why... Because when you're not home, it's makes everyone else at home feel like they don't know what you're doing, and that you may not be safe... and also financially you are not contributing to the family because you're gone. So it can be a safety issue, a cultural issue, and the financial stability issue. 


\section{$\underline{\text { Discrimination }}$}

White males and underrepresented groups perceived discrimination along their degree and career pursuit. Discrimination based on gender was the most commonly mentioned form of discrimination discussed by both undergraduates ( 5 undergraduates) and recent hires ( 5 recent hires). For example, a white female undergraduate stated:

When I interviewed at [commercial forestry company], the guy expressed doubt that I could actually do the physical labor. So that was why I ended up getting an internship at a nature center because I didn't want to work for someone like that. It might narrow my career choices ...

White male undergraduates ( 1 undergraduate) and recent hires ( 3 recent hires) discussed experiencing reverse discrimination due to diversity initiatives. However, recent hires from ethnic/racial minorities also perceived discrimination. For example, a black female discussed:

I am a black female and I'm 30 years old...I have white males who are in the 45 to 65 age range asking me what I'm doing?.... and how long I've been doing this? And it's like wait, you don't know that other guy over there and I don't see anybody questioning him. And it kind of makes me feel like what I'm doing isn't legitimate...

Notably, underrepresented undergraduates did not discuss discrimination based on ethnicity/race. Yet, students from non-traditional backgrounds did perceive being treated differently by faculty at the university ( 5 undergraduates). For example, a white male discussed being treated differently because of a non-traditional background:

I feel like there's a stereotype of big burly men with beards and I definitely do not fit in that category whatsoever. And that's one of the reasons, believe it or not, that they pushed me towards arboriculture... because I just didn't fit in...

\section{Discussion}

Similar to a study by Lent et al. (2002) examining barriers in math and sciences using the SCCT, this study found four main thematic categories of barriers for both undergraduates and recent hires: financial, institutional, social and familial, and discrimination (Betz, 2008). 
However, this study was able to identify support and barrier themes that are specific to natural resource majors using qualitative methods. Specifically, barriers related to non-traditional backgrounds in the field, lack of family knowledge of the field (particularly in underrepresented groups), and pressure to relocate in the field were uniquely identified by this study. The similarity of supports and barriers discussed by natural resource majors and recent hires highlights the types of questions and themes that should be included on future quantitative work applying the SCCT to the field. In addition, this study highlights the need to include a widerange of support and barrier themes in quantitative measure, especially when working with culturally diverse populations.

The most notable difference between the two groups was that undergraduates experienced increased barriers because of non-traditional backgrounds, whereas recent hires experienced increased barriers because of ethnicity/race. In natural resource degree programs, non-traditional students can be considered an underrepresented group, and therefore may face increased barriers similar to ethnic/racial minorities in non-traditional careers (Luzzo \& McWhiter, 2001). Consequently, natural resource programs and organizations may need to use specialized recruitment and retention techniques for ethnic/racial minorities, as well as nontraditional students. For example, natural resource programs could offer summer (or semester) short courses to students with less experience in natural resources to prepare them for the major. Additionally, special early work experiences, such as internships and practicums could increase comfort level of non-traditional students during course work and social interactions. Natural resource organizations could advertise to minority-serving universities and urban high schools to address the lack of knowledge and professional support barriers. 
Overall, a lack of knowledge of the natural resource field was the most mentioned barrier, which is consistent with past research findings on natural resource-related careers (Adams \& Moreno, 1998; Maughan et al., 2001; Outley, 2008). The lack of knowledge persisted through high school, undergraduate education, graduate school, and even into beginning a career for some young adults. Therefore, natural resource programs and organizations may want to focus efforts on early and extensive advertisement of major and career options in high school. Using a hands-on approach and hosting natural resource program fairs, which introduce high school students to natural resource programs may be an effective way to recruit (recommended by 6 undergraduates). In addition, natural resource program and organization advertisement should continue at the undergraduate and graduate level to compensate for lack of awareness at the high school level. At the organization level, environmental education programs could include information on potential career and internships opportunities to ensure students of all ages are exposed to these options.

Lack of knowledge may also impact the level of familial support for pursuing a natural resource degree and career, especially for underrepresented groups. Family support may be of particular importance in ethnic groups with traditional collectivist values (e.g. Mexican Americans), individuals in more isolated communities (e.g. rural Appalachia), and women (Ali \& Saunders, 2006; Flores \& O’Brien, 2002; Wetterson et al., 2005), especially when pursuing a non-traditional career. Social supports have also been shown to neutralize impacts of barriers along the academic or career path of women and ethnic minorities (Lent, Lopez, Sheu, \& Lopez, 2011; Quimby \& O’Brien, 2004). Therefore, natural resource programs and organizations need to educate not only young adults, but also families about career options and pathways consistently throughout career development. Additionally, when trying to attract 
underrepresented groups, natural resource programs and organizations may want to reach out and connect to organizations and social groups that focus on underrepresented groups in natural resources, such as Minorities in Agriculture and Natural Resource Related Sciences.

Although discrimination did not prevent undergraduates and recent hires from pursuing a degree or career, they perceived discrimination as a student or new professional. Unfortunately, due to time and funding constraints this study was not able to interview young adults that did not enter the natural resource field, but past studies have found that discrimination has prevented young adults from entering natural resource careers (e.g. Chesney, 1981; Washington \& Rodney, 1986). For the young adults interviewed in this study, discrimination may be a factor that impacts retention rather than recruitment. Therefore, natural resource degree programs and organizations may need to offer extra support systems for female students, non-traditional students, and ethnic/racial minorities. In addition, training focused on effective cultural and generational communication techniques given at all levels of employment throughout an organization could help boost retention.

In conclusion, these results uncovered specific barriers facing young adults and underrepresented groups pursuing natural resources. The unique barriers perceived by specific groups highlight the need to design recruitment and retention techniques for specific target populations. By carefully designing support systems for young adults and underrepresented groups, natural resource organizations can help them overcome barriers and enter the natural resource workforce. 
Furthermore, the successful, but limited application of the SCCT to natural resourcerelated career choice indicates potential for future research in this area. It is critical that researchers continue to focus efforts on the barriers to young adults, if the impending human resource crisis is to be alleviated. Future research should include young adults that did not successfully navigate a natural resource career or were unable to overcome barriers. 


\section{References}

Adams, C.E., \& M. Moreno. (1998). A comparative study of natural resource professionals in minority and majority groups in the Southeastern United States. Wildlife Society Bulletin, 4, 971-981.

Ali, S. R., \& J.L. Saunders. (2006). College expectations of rural Appalachian youth: An exploration of social cognitive career theory factors. Career Dev Quarterly, 55, 38-52.

Bandura, A. (1986). Social foundations of thought and action: A social cognitive theory. Prentice-Hall, Englewood Cliffs, NJ. 617p.

Betz, N.E. (2008). Advances in vocational theories. P. 357-374 in Handbook Of Counseling Psychology. S. Brown and R. Lent (eds.). Wiley, New York, NY.

Bowman, M.L., \& C.L. Shepard. (1985). Introducing minorities to natural resource career opportunities. Ohio Journal of Science, 85, 29-33.

Carnevale, A.P., J. Strohl, \& M. Melton. (2011). What is it worth? The economic values of college majors. Available online at http://cew.georgetown.edu/whatsitworth; last accessed Sept. 9, 2013.

Chesney, C.E. (1981). Should racial minorities consider careers in natural resources? Journal of Non-white Concerns, 41(4), 146-153.

Copeland, C.W. (2011). The federal workforce: Characteristics and trends. Congressional Research Service Technical Report: RL34685. 28p.

Diaz, W. (2010). Relationship of perceived barriers to career self-efficacy among Latino undergraduates at a New England regional public university. Ph.D. dissertation, Johnson \& Wales Univ., Providence, Rhode Island. 164p.

Esters, L.T. (2007.) Factors influencing postsecondary education enrollment behaviors of urban agricultural education students. Career and Technical Education Research, 32, 79-98.

Flores, L. Y., \& K.M O’Brien. (2002). The career development of Mexican American adolescent women: A test of social cognitive career theory. Journal of Counseling Psychology, 49, 14-27.

Lent, R.W. (2005). A social cognitive view of career development and counseling. P. 101-237 in Career development and counseling: Putting theory and research to work. S.D. Brown and R.W. Lent (eds.). Wiley, New York, NY.

Lent, R.W., \& S.D. Brown. (2006). On conceptualizing and assessing social cognitive constructs in career research: A measurement guide. Journal of Career Assessment, 14, 12-35. 
Lent, R.W., S.D. Brown, \& G. Hackett. (1994). Toward a unifying social cognitive theory of career and academic interest, choice, and performance. Journal of Vocational Behavior, 45, 79-122.

Lent, R. W., S.D. Brown, \& G. Hackett. (2000). Contextual supports and barriers to career choice: A social cognitive analysis. Journal of Counseling Psychology, 47, 36-49.

Lent, R.W., S.D. Brown, R. Talleyrand, E.B. McPartland, T. Davis, S.B. Chopra, M.S. Alexander, V. Sutherakaran, \& M. Chai. (2002). Career choice barriers, supports, and coping strategies: College students' experiences. Journal of Vocational Behavior, 60, 6172 .

Lent, R.W., F.G. Lopez, H. Sheu, \& A.M. Lopez. (2011). Social cognitive predictors of the interests and choices of computing majors: Applicability to underrepresented students. Journal of Vocational Behavior, 78, 184-192.

Luzzo, D. A., \& E.H. McWhirter. (2001). Sex and ethnic differences in the perception of educational and career-related barriers and levels of coping efficacy. Journal Counseling Development, 79, 61-67.

Maughan, O.E., D.L. Bounds, S.M. Morales, \& S.V. Villega. (2001). A successful educational program for minority students in natural resources. Wildlife Society Bulletin, 29, 917-928.

Newman, I., \& C.R. Benz. (1998). Qualitative-quantitative research methodology. Exploring the interactive continuum. Southern Illinois University Press, Carbondale and Edwardsville, IL. 240p.

Organization for Tropical Studies. (2007). Advisory Committee for Academic Diversity manual of best practices for recruiting and retaining underrepresented groups in ecology and the environmental sciences. Found online at http://www.obfs.org/assets/docs/humandiversity/manual-bestpractice.pdf; last accessed Sept. 92013.

Outley, C.W. (2008). Perceptions of agriculture and natural resource careers among minority students in a national organization. USDA For. Serv. Gen. Tech. Rep. PSW-GTR-210. $15 \mathrm{p}$.

Patton, M.Q. (2002). Qualitative research and evaluation methods ( $3^{\text {rd }}$ ed.). Sage Publication Ltd.. Thousand Oaks, CA. 598p.

Quimby, J. L., \& K.M. O’Brien. (2004). Predictors of student and career decisionmaking self-efficacy among nontraditional college women. Career Development Quarterly, 52, 323-339.

Sharik, T.L., R.J. Liliehold, \& Richardson. Factors influencing undergraduate enrollment trends in natural resources. Paper, $9^{\text {th }}$ Biennial Conference on University Education in Natural Resources, Fort Collins, CO., March 22, 2012. 
Stemler, S. (2001). An overview of content analysis. Practical Assessment, Research, and Evaluation, 7. Available online at http://PAREonline.net/getvn.asp?v=7\&n=17; last accessed Sept. 9, 2013.

Taylor, D. (2008). Diversity and the Environment: Myth-Making and the Status of Minorities in the Field. Research in Social Problems and Public Policy, 15, 89-148.

Thomson, S.B. (2011). Sample size and grounded theory. Journal of Admininstration and Governance, 5, 45-52.

U.S Department of Commerce Economics and Statistics Administration. (2011). Overview of race and Hispanic origin: 2010. 2010 Census Briefs. U.S. Census Bureau Tech. Rep. $24 \mathrm{p}$.

Washington, W.J. \& H.E. Rodney. (1986). How do students learn about natural-resource careers? Journal of Forestry, 81, 22-24.

Wettersten, K. B., A. Guilmino, C.G. Herrick, P.J. Hunter, G.Y. Kim, T. Beecher, \& et al. (2005). Predicting educational and vocational attitudes among rural high school students. Journal of Counseling Psychology, 52, 658-663.

Wildman, M., \& R.M. Torres. (2001). Factors identified when selecting a major in agriculture. Journal Agricultural Education, 42(2), 46-55. 
Figure 1.



Figure 1. The SCCT model: variables in shaded boxes represent the core/proximal social cognitive and contextual variables (Lent et al, 1994). 
Table 1. Demographic Data of 22 undergraduate natural resource majors.

\begin{tabular}{|c|c|c|}
\hline & & $\begin{array}{c}\text { \# of } \\
\text { Students }\end{array}$ \\
\hline \multirow[t]{2}{*}{ Gender } & Female & 9 \\
\hline & Male & 13 \\
\hline \multirow[t]{6}{*}{ Race/Ethnicity } & White & 14 \\
\hline & Black & 4 \\
\hline & Lebanese/White & 1 \\
\hline & Asian & 1 \\
\hline & Black/White & 1 \\
\hline & $\begin{array}{l}\text { Native American/ } \\
\text { White }\end{array}$ & 1 \\
\hline \multirow[t]{4}{*}{ Class Level } & Freshman & 1 \\
\hline & Sophomore & 3 \\
\hline & Junior & 10 \\
\hline & Senior & 8 \\
\hline
\end{tabular}


Table 2. Demographic data of 22 recent hires at the U.S. Fish and Wildlife Service.

\begin{tabular}{|c|c|c|c|c|c|}
\hline & & $\begin{array}{c}\text { \# of Recent } \\
\text { Hires }\end{array}$ & & & $\begin{array}{c}\text { \# of Recent } \\
\text { Hires }\end{array}$ \\
\hline \multirow[t]{3}{*}{ Gender } & Female & 14 & Region & 2 & 4 \\
\hline & Male & 8 & & 3 & 2 \\
\hline & & & & 4 & 2 \\
\hline \multirow[t]{5}{*}{ Race/Ethnicity } & White & 17 & & 5 & 5 \\
\hline & Black & 2 & & 6 & 3 \\
\hline & Hispanic/Latino & 1 & & 7 & 1 \\
\hline & Hispanic/Asian & 1 & & 8 & 1 \\
\hline & Black/White & 1 & & 9 & 4 \\
\hline \multirow[t]{5}{*}{ Education Level } & Associates & 2 & Year of Employment & 2009 & 2 \\
\hline & Bachelors & 5 & & 2010 & 7 \\
\hline & Masters & 13 & & 2011 & 6 \\
\hline & Juris Doctor & 2 & & 2012 & 6 \\
\hline & & & & 2013 & 1 \\
\hline
\end{tabular}


Table 3. Barriers faced by undergraduates and recent hires followed by the number of participants that discussed that barrier.

\begin{tabular}{|c|c|c|c|}
\hline Undergraduates & $\#$ & FWS Recent Hires & \# \\
\hline Financial & & \multicolumn{2}{|l|}{ Financial } \\
\hline Lack of Scholarships in Field & 7 & Low Pay in Field & 5 \\
\hline College Tuition & 6 & Moving Costs & 5 \\
\hline Earning Potential in Field & 3 & University Course Cost & 3 \\
\hline Need to Contribute to Family & 1 & Inability to Take Unpaid Internships & 3 \\
\hline Single Parent Income & 1 & Lack of Loan Repayment Plan & 1 \\
\hline Institutional & & Institutional & \\
\hline Lack of Knowledge of the Field & 16 & Lack of Knowledge of the Field & 14 \\
\hline Non-Tradition Background & 9 & Competitive Hiring Practices & 13 \\
\hline Natural Resource Course Work & 8 & Lack of Required Courses & 11 \\
\hline Unsure How to Get Experience & 4 & Specific Job Descriptions & 7 \\
\hline First Generation College Student & 2 & Lack of Job Openings & 6 \\
\hline Lack of Job Openings in the Field & 2 & Transition to Full-time & 5 \\
\hline \multirow[t]{8}{*}{ Older Faculty } & 1 & FWS Structure & 5 \\
\hline & & Unclear Communication with HR & 4 \\
\hline & & University Unaware of FWS Programs & 4 \\
\hline & & Moving Requirements & 3 \\
\hline & & Long Application Process & 2 \\
\hline & & Lack of Skills & 2 \\
\hline & & Veterans Preference & 2 \\
\hline & & Wage Grade vs. GS & 1 \\
\hline Familial and Social & & Familial and Social & \\
\hline Lack of Family Understanding of the & 6 & Cultural Dissonance & 5 \\
\hline Field & & Lack of Work/Life Balance & 4 \\
\hline Parents Wanted a Different Major & 6 & Lack of Family Understanding of the & 3 \\
\hline Lack of Friend Understanding of the & 5 & Field & \\
\hline Field & & Discouragement from Natural Resources & 3 \\
\hline Did Not Fit in with Classmates & 5 & Inner-city to Rural Area Transition & 1 \\
\hline Intimidated Due to Lack of Experience & 3 & & \\
\hline College-Related Social Distractions & 2 & & \\
\hline Discrimination & & Discrimination & \\
\hline Discrimination Based on Gender & 5 & Discrimination Based on Gender & 5 \\
\hline Faculty Insensitive to Non-Tradition & 5 & Discrimination Based on Age & 5 \\
\hline Background & & Reverse Discrimination & 3 \\
\hline Reverse Discrimination & 1 & Discrimination Based on Race/Ethnicity & 2 \\
\hline
\end{tabular}


APPENDIX A: Email to recent hires

Dear Recent Hire-

We are conducting a study for the US Fish \& Wildlife Service (FWS), and you were recommended as a person to contact for more information by . We'd like to interview a select number of FWS employees between 18-30 years of age that were hired as full-time, permanent employees within the past three years. The purpose of this study is to assess the FWS's receptivity to hiring young adults (aged 18-30 years), and the barriers faced by young adults throughout the application/hiring/employment process. The results of the study will assist the FWS to more effectively recruit, hire and retain young adults. The interview should only take about 30-40 minutes.

Your participation in this interview is voluntary, and your name will not be attached to any data. Your decision to participate will not affect your position within the FWS. If you decide to participate, you may withdraw at any time. You may also refuse to answer any questions you do not want to answer and remain in the study. You have the right to ask questions about the research project, obtain a copy of the results, and have your privacy respected throughout the process. The protocols used will be approved by the West Virginia University's Institutional Review Board.

We would like to set up a phone interview at a time that is convenient for you. We would appreciate if you would respond to this email and let us know whether or not you are interested in participating, and which days and times are most convenient for you. Please provide your phone number, so we can follow up with you. If you need more information at this time, please let us know.

Thank you for your help in completing this important study,

Kelly Balcarczyk, Ph.D. student

Dr. Dave Smaldone

Dr. Steve Selin

Division of Forestry and Natural Resources

Recreation, Parks \& Tourism Program

West Virginia University 
APPENDIX B: Recent hire interview

1. Describe your job selection process.

a. How did you search for jobs?

b. Why did you apply to certain jobs? FWS jobs?

c. When did you first hear about/consider the FWS as a career option?

d. What factors helped you decide to accept a position with FWS?

e. What was your first FTE position with the FWS?

f. How did you enter the pathway to FTE with the FWS (SCEP, PMF, competitive hire, etc.)?

g. Did you volunteer/intern/work as a temporary employee for a natural resource organization or agency before working with the FWS? As a FTE? Which agency?

2. Did you encounter any barriers/obstacles in obtaining a job with the FWS? If, so please describe them.

a. What financial barriers, if any, did you encounter in your pursuit of a job with the FWS (i.e. lack of scholarships, needed a paying job instead of internship, didn't have to money to move to a job)?

b. What school or work-related barriers, if any, did you encounter in your pursuit of a job with the FWS (i.e. lack of knowledge about FWS jobs, lack of natural resource course options, lack of credits needed to meet the education requirements for FWS jobs)?

c. What social or familial barriers, if any, did you encounter in your pursuit of a job with the FWS (i.e. mother/father did not support a natural resource career, friends did not see the value of college)?

d. What discrimination barriers, if any, did you encounter in your pursuit of a job with the FWS?

e. Did you encounter any additional barriers not discussed in the previous questions? If so, please describe them.

3. What types of support, or help, did you receive in your pursuit of a job with the FWS?

a. What financial supports, if any, did you receive in your pursuit of a job with the FWS (scholarships, stipends, parental monetary support)?

b. What school or work-related assistance, if any, did you receive in your pursuit of a job with the FWS (i.e. career counseling at your university, on-the-job training, early work experience, job placement assistance)?

c. What social or familial support, if any, did you receive in your pursuit of a job with the FWS (i.e. mother/father value a natural resource career, friends enjoy outdoor activities, hunting was a past-time in your family)?

d. Did you have any role models or mentors that supported you in your pursuit of a job with the FWS? If so, who were they, and describe the role they played?

e. Did you receive any additional supports not discussed in the previous questions? If so, please describe them.

4. How did you overcome any barriers/obstacles to obtaining a job with FWS? 
5. Please describe one thing the FWS has done to meet your needs/wants or supported your ideas as a young adult working for the agency.

6. Please describe one thing the FWS can do to improve, in order to meet your needs/wants or support your ideas as a young adult working for the agency.

7. Have you received the proper training for your job?

a. Did your previous training, schooling or jobs prepare you well for a job with the FWS? What aspects of your previous experience best prepared you for a job with the FWS?

b. What job specific training and orientation did you receive upon entering the FWS? Did you receive on-the-job training or attend training seminars and workshops? What aspects of your job specific training were most beneficial?

c. Describe any additional training that would be helpful to you as a recent hire.

8. On a scale of 1 to 7 , how satisfied are you with your position in the FWS? One being "very dissatisfied", 4 being "neutral", and 7 being "highly satisfied".

a. Please describe one thing the FWS can do to increase your job satisfaction.

b. Given your current level of satisfaction, how long do you plan to work with the FWS? Why?

c. Do you think a continued career with the FWS fits with your life goals? Would you feel satisfied with a continued career with the FWS? Why or why not?

9. Do you think you have the potential to be promoted in the FWS? Why or why not?

a. How long are you willing to wait to be promoted within the FWS?

10. In general, do you think the FWS is receptive to hiring young adults? Young adults in underrepresented groups?

11. What recommendations can you make to improve FWS job retention of young adults (ages $18-30)$ ? Young adults in underrepresented groups?

\section{Demographics}

What is your gender?

$\square$ Male

$\square$ Female

What is your age? years old

What is the highest grade of school or year of college that you completed?

(Check only one.)

$\square$ Less than high school

$\square$ High school graduate or GED

$\square$ Some college or associate degree

$\square$ Four year college degree 
$\square$ Masters, doctoral, or professional degree

Are you Hispanic or Latino?

$\square$ Yes $\quad \square$ No

Which racial groups do you identify with?

$\square$ Native American or Alaska Native

$\square$ Asian

Black or African American

$\square$ Native Hawaiian or other Pacific Islander

White

What year did you become a permanent employee of the FWS?

(year)

At how many different FWS sites have you worked? sites as a permanent employee sites as intern, seasonal, etc. employee

How many years have you worked at your current site?

years as a permanent employee at current site years as intern, seasonal, etc. employee, at any FWS site

In which region do you currently work? region

At which type of site do you work? (Check one)

$\square$ Washington D.C.

$\square$ Regional

$\square$ Field

In which program area do you work? (Check one)

$\square$ Wildlife and Sport Fish Restoration Programs

$\square$ National Wildlife Refuge System

$\square$ Migratory Birds

$\square$ Fisheries and Habitat Conservation

$\square$ Endangered Species

$\square$ International Affairs

$\square$ Law Enforcement

$\square$ Budget, Planning, and Human Capital

$\square$ Business Management and Operations

$\square$ Information Resources and Technology

What is your GS level? 
What is your functional job title?

Can you suggest 3 other FWS recent hires that you think might be willing to participate in this study? If so, please provide their names, \& contact info. 


\section{APPENDIX C: Email to Undergraduates}

\section{Dear Undergraduate,}

We are conducting a study for the US Fish \& Wildlife Service (FWS), and you were recommended as a person to contact for more information by We'd like to interview a select number of West Virginia University and Alabama A\&M University undergraduates on the barriers and supports to pursuing a natural resource degree and career. The results of the study will assist West Virginia University, Alabama A\&M, and the FWS to more effectively recruit and retain young adults interested in natural resource careers. If you are interested, we would like to interview you as part of this research. Data collection is being conducted by Kelly Balcarczyk, and supervised by Dr. Dave Smaldone, Associate Professor in the Recreation, Parks \& Tourism Program at West Virginia University. The interview should only take about $20-30$ minutes.

Your participation in this interview is voluntary, and your name will not be attached to any data. If you decide to participate, you may withdraw at any time. You may also refuse to answer any questions that you do not want to answer and remain in the study. You have the right to ask questions about the research project, obtain a copy of the results, and have your privacy respected throughout the process. The protocols used will be approved by the West Virginia University's Institutional Review Board.

We would like to set up a phone (or skype) interview at a time that is convenient for you. We would appreciate if you would respond to this email and let us know whether or not you are interested in participating, and which days and times are most convenient for you. Please provide your phone number, so we can follow up with you. If you need more information at this time, please let us know.

Thank you for your help in completing this important study,

Kelly Balcarczyk, Ph.D. student; (315) 604-1054

Dr. Dave Smaldone

Dr. Steve Selin

Division of Forestry and Natural Resources

Recreation, Parks \& Tourism Program

West Virginia University 
APPENDIX D: Undergraduate interview

12. Describe your degree program/major selection process.

h. How did you learn about potential college majors?

i. When did you first hear about/consider a natural resource major as an option?

j. What factors helped you decide to enter a natural resource degree program at WVU?

a. What was the most significant factor that led to your choice of a natural resource degree?

b. Did the fact that WVU offers an SAF accredited degree have any bearing on your decision on entering the degree program?

k. Have you volunteered/interned/worked for a natural resource organization or agency? Which agency?

13. Did you encounter any barriers/obstacles to pursuing a natural resource degree? If, so please describe them.

a. What financial barriers, if any, did you encounter in your pursuit of a natural resource degree (i.e. lack of scholarships, lack of job, didn't have to money to move for college)?

b. What school or work-related barriers, if any, did you encounter in your pursuit of a natural resource degree (i.e. lack of knowledge about natural resource majors, lack of knowledge about potential natural resource jobs)?

c. What social or familial barriers, if any, did you encounter in your pursuit of a natural resource degree (i.e. mother/father did not support a natural resource major, friends did not see the value of college)?

d. What discrimination barriers, if any, did you encounter in your pursuit of natural resource degree?

e. Did you encounter any additional barriers not discussed in the previous questions? If so, please describe them.

14. What types of support, or help, did you receive in your pursuit of a natural resource degree?

a. What financial supports, if any, did you receive in your pursuit of a natural resource degree (scholarships, stipends, parental monetary support)?

b. What school or work-related assistance, if any, did you receive in your pursuit of a natural resource degree (i.e. career counseling at your university/high school, early work experience, college placement assistance)?

c. What social or familial support, if any, did you receive in your pursuit of a natural resource degree (i.e. mother/father value a natural resource major, friends enjoy outdoor activities, hunting was a past-time in your family)?

d. Did you have any role models or mentors that supported you in your pursuit of a natural resource degree? If so, who were they, and describe the role they played?

e. Did you receive any additional supports not discussed in the previous questions? If so, please describe them. 
15. How did you overcome any barriers/obstacles to pursuing a natural resource degree?

16. Do you feel you are receiving the proper training for your future career?

a. Do you feel that your current major is preparing you well for your future career?

b. Do you feel that your program offered enough hands-on or field-based learning opportunities?

c. Do you feel your work experience is/has prepared you well for your future career?

d. What aspects of your previous experience best prepared you for a job in natural resources?

e. Describe any additional training that would be helpful to you as a natural resource major.

17. Do you think you have the potential to obtain a career in natural resources? Why or why not?

a. What would your ideal natural resource career be?

18. Are you aware of the U.S. Fish and Wildlife Service?

a. How did you become aware of the U.S. Fish and Wildlife Service?

b. Are you aware of the U.S. Fish and Wildlife Service Youth in the Great Outdoors Initiative?

c. Are you aware of careers offered by the U.S. Fish and Wildlife Service?

19. Would you consider a career with the U.S Fish and Wildlife Service? Why or why not?

a. Do you think you have the potential to obtain a career with the FWS? Why or why not?

b. Please describe one thing that the FWS can do to increase the likelihood of you applying for a job with them.

c. Do you think a career with the FWS fits with your life goals? Would you feel satisfied with a career with the FWS? Why or why not?

20. What recommendations can you make to improve the recruitment of young adults into natural resource degree programs? Young adults in underrepresented groups?

\section{Demographics}

What is your gender?

$\square$ Male

$\square$ Female

What is your age? years old

What year are you in at your university?

$\square$ Freshman

$\square$ Sophomore

$\square$ Junior

$\square$ Senior 
Are you Hispanic or Latino?

$$
\square \text { Yes } \quad \square \text { No }
$$

With which racial groups do you identify?

$\square$ Native American or Alaska Native
$\square$ Asian
$\square$ Black or African American
$\square$ Native Hawaiian or other Pacific Islander
$\square$ White

What year did you become a natural resource major at WVU? (year)

Did you pursue other majors before transferring to natural resources? If so, which?

Did you attend any other universities before entering WVU? If so, which? 